\title{
Dynamic Capital Structure with Callable Debt and Debt Renegotiations
}

Christensen, Peter Ove; Flor, Christian Riis; Lando, David; Miltersen, Kristian

\author{
Document Version \\ Final published version \\ Published in: \\ Journal of Corporate Finance \\ DOI: \\ 10.1016/j.jcorpfin.2013.09.001 \\ Publication date: \\ 2014 \\ License \\ CC BY-NC-ND
}

Citation for published version (APA):

Christensen, P. O., Flor, C. R., Lando, D., \& Miltersen, K. (2014). Dynamic Capital Structure with Callable Debt and Debt Renegotiations. Journal of Corporate Finance, 29, 644-661.

https://doi.org/10.1016/j.jcorpfin.2013.09.001

Link to publication in CBS Research Portal

\section{General rights}

Copyright and moral rights for the publications made accessible in the public portal are retained by the authors and/or other copyright owners and it is a condition of accessing publications that users recognise and abide by the legal requirements associated with these rights.

\section{Take down policy}

If you believe that this document breaches copyright please contact us (research.lib@cbs.dk) providing details, and we will remove access to the work immediately and investigate your claim.

Download date: 26. Apr. 2023
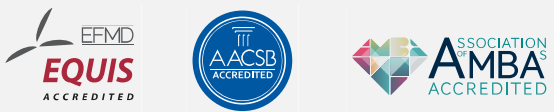
NOTICE: this is the author's version of a work that was accepted for publication in Journal of Corporate Finance. Changes resulting from the publishing process, such as peer review, editing, corrections, structural formatting, and other quality control mechanisms may not be reflected in this document. Changes may have been made to this work since it was submitted for publication. A definitive version was subsequently published in Journal of Corporate Finance, VOL29, December 2014. DOI:10.1016/j.jcorpfin.2013.09.001

\title{
Dynamic Capital Structure with Callable Debt and Debt Renegotiations
}

Peter Ove Christensen ${ }^{\mathrm{a}}$, Christian Riis Flor ${ }^{\mathrm{b}}$, David Lando ${ }^{\mathrm{c}, *}$, Kristian R. Miltersen ${ }^{\mathrm{c}}$

${ }^{a}$ Dept. of Economics and Business, Aarhus University, Fuglesangs Allé 4, 8210 Aarhus $V$, Denmark.

${ }^{b}$ Dept. of Business and Economics, University of Southern Denmark, Campusvej 55, 5230 Odense $M$, Denmark.

${ }^{c}$ Dept. of Finance, Copenhagen Business School, Solbjerg Plads 3, 2000 Frederiksberg, Denmark.

\begin{abstract}
We consider a dynamic trade-off model of a firm's capital structure with debt renegotiation. Debt holders only accept restructuring offers from equity holders backed by threats which are in the equity holders' own interest to execute. Our model shows that in a complete information model in which taxes and bankruptcy costs are the only frictions, violations of the absolute priority rule (APR) are typically optimal. The size of the bankruptcy costs and the equity holders' bargaining power affect the size of APR violations, but they have only a minor impact on the choice of capital structure.
\end{abstract}

JEL classification: G32, G33, G13

Keywords: Dynamic capital structure, debt restructuring, violation of absolute priority

\footnotetext{
*Corresponding author. Phone: +45 38153613.

Email addresses: pochristensen@econ.au.dk (Peter Ove Christensen), crf@sam.sdu.dk (Christian Riis Flor), dl.fi@cbs.dk (David Lando), krm.fi@cbs.dk (Kristian R. Miltersen)
} 


\section{Introduction}

Empirical evidence suggests that for most firms in financial distress, debt and equity holders agree - either voluntarily or as part of a Chapter 11 process - to restructure the firm's capital thereby allowing the firm to continue operation, see Weiss (1990), Gilson et al. (1990), and Morse and Shaw (1988). We consider a dynamic capital structure model in which the going concern value of the firm makes debt renegotiation optimal for debt and equity holders. If the firm is in financial distress, the equity holders can make a take-it-or-leave-it offer to the existing debt holders in order to reestablish an optimal capital structure for the firm. The debt holders always have the option to reject the offer, but their decision whether to accept or reject depends on what they anticipate will happen if they reject. A critical feature of our model is that debt holders do not accept offers from equity holders which are not credible. An example of a non-credible threat is if equity holders threaten to liquidate the firm even if it would be better for them to keep servicing the existing debt. In equilibrium, the equity holders only make renegotiation offers which are accepted by the debt holders, but the off-the-equilibrium-path rejection values of debt and equity are the key in determining the equilibrium offer. We find that debt holders rationally accept deviations from the absolute priority rule as the outcome of the renegotiation game. The intuition is that equity holders know that non-credible threats will be rejected by debt holders and, hence, equity holders postpone their renegotiation offer to the point at which liquidation becomes a credible threat. At this point it is rational for the debt holders to accept deviations from the absolute priority rule, since liquidation is the alternative.

We also allow for callable debt and reissuance of debt when the firm does well and, hence, our model extends and unifies several strands of the 
literature on dynamic capital structure. Compared to existing models, the combination of renegotiation and callability significantly increases the tax advantage to debt.

We consider a firm with a simple capital structure consisting of equity and a single class of callable perpetual debt. Following Goldstein et al. (2001), we use the firm's earnings before interest and taxes (EBIT) as the driving state variable. For an initial level of EBIT, an optimal capital structure is chosen to maximize firm value by trading off the tax advantage to debt, the cost of financial distress, and future restructuring costs. Subsequent to the issuance of debt and equity, the equity holders continuously decide whether to continue servicing the existing debt or to restructure the firm's capital. As the firm's EBIT increases, equity holders prefer more debt to better exploit the tax shield. As the firm's EBIT decreases, the equity holders prefer less debt in order to reduce the cost of financial distress. The initial values of debt and equity rationally reflect the equity holders' ex-post incentives to restructure as well as the payoffs received if restructuring occurs.

For reasons that will be explained when we define our model, we solve for debt and equity values in a case where there are finitely many renegotiation options. The starting point is first to solve a case with no renegotiation possibility at the lower boundary. This benchmark case is comparable to Goldstein et al. (2001), and is in accordance with classical models such as Black and Cox (1976), Merton (1974), and Leland (1994). In these models, the firm is liquidated at the lower boundary, and the tax advantage to debt is lost permanently. Our benchmark model deviates from these models by assuming that the value of the firm's production technology in liquidation is equal to the value for a new entrepreneur who can start afresh and optimally lever the firm's assets. 
With debt renegotiation, equity holders may continue to service the debt after a rejection by the debt holders. To handle this, we need a friction that leaves the firm in a different shape after one renegotiation round consisting of an offer, a rejection, and a continuation of debt service. The friction is the loss of one renegotiation option, which brings the firm one step closer to the case with forced liquidation at the lower boundary. This friction is similar in spirit to the finite number of sequential offers refinement of the Nash equilibria in the Rubinstein bargaining game, cf. Rubinstein (1982, 1987).

Our model shares an important feature with strategic debt service models, cf. Anderson and Sundaresan (1996), Mella-Barral and Perraudin (1997), Hege and Mella-Barral (2005), and Hackbarth et al. (2007): When liquidation is costly, the debt and equity holders have a common interest in saving the costs of bankruptcy. There are two key differences between our debt renegotiation model and the strategic debt service models. First, in strategic debt service models, a failed renegotiation proposal leads to a forced liquidation of the firm. They rule out the possibility that equity holders may continue servicing the debt with the existing coupon payments, i.e., that the assumed bankruptcy threat to force concessions from the debt holders may not be a credible threat. In our model, we insist on credible threats which forces equity holders to postpone their restructuring offer. Second, in the strategic debt service models, there is no restructuring of the firm's capitalthe equity holders only bargain in order to obtain temporary coupon relief. François and Morellec (2004), Galai et al. (2007), and Broadie et al. (2007) look at settings in which debt is not serviced while in Chapter 11, but the (original) coupon must be paid if the firm leaves Chapter 11. These papers incorporate important aspects of the Chapter 11 code, e.g., the automatic 
stay, but a successful exit of Chapter 11 does not solve the underlying capital structure (financial distress) problem. Annabi et al. (2010) consider the outcome of Chapter 11 as a non-cooperative game. They focus on the judge's role, and the random intervention leads to a game in multiple rounds, but they do not consider the firm's optimal capital structure.

Goldstein et al. (2001) find that their dynamic capital structure model gives lower leverage ratios than static capital structure models, ceteris paribus, since the firm can subsequently increase its outstanding debt, if EBIT increases sufficiently. By adding debt renegotiation to the model, we find that leverage ratios increase compared to the results of Goldstein et al. (2001). This is due to the fact that debt renegotiation reduces the negative impact of financial distress relatively to a setting in which liquidation is the only outcome of financial distress. The introduction of debt renegotiations increases the tax advantage to debt by $50 \%$ relative to a dynamic capital structure model with no debt renegotiation for realistic parameter values.

Our model gives a simple explanation of the violation of the absolute priority rule for firms in financial distress. Such violations are well documented in the empirical literature, see Weiss (1990), Eberhart et al. (1990b), Betker (1995), Bris et al. (2006), and Altman and Hotchkiss (2010). On the equilibrium path, it is perfectly rational for the debt holders to accept a renegotiation proposal from the equity holders which leaves some value to the equity holders even though the debt holders do not recover their full principal. The reason is that a rejection by the debt holders does not necessarily force an immediate liquidation of the firm. Equity holders may continue servicing the debt with the promised coupon until the conditions become even worse. We show that equity holders' bargaining power has a significant impact on the absolute priority violations, but that it only has a minor impact 
on the choice of capital structure and on the ex-ante optimally levered firm value. Hackbarth et al. (2007) also consider anticipated deviations from absolute priority that depend on the toughness of the bankruptcy regime, but the violations are not a rational model outcome.

In addition, our model predicts that the bankruptcy costs have almost no impact on the firm's optimal capital structure policy. In fact, in our model the firm is always more valuable alive than liquidated, and debt renegotiation ensures that liquidation never occurs. Hence, bankruptcy costs only affect the off-the-equilibrium-path values of debt and equity and the size of the APR violations. We do not address why restructurings occur in some cases and liquidation in others, as in for example Broadie et al. (2007).

As noted, our model provides a number of empirical implications. Note, however, that these empirical implications are relevant at recapitalization points, i.e., for newly optimally levered firms. The distance between the upper and lower boundary at which the firm is recapitalized, however, is quite large. Therefore, the important caveat of Strebulaev (2007) applies, i.e., cross-sectional analysis of leverage, which do not recognize that firms are away from their optimal leverage most of the time, may not be consistent with our predictions. In our model, the initial choice of leverage is a strong predictor of future leverage, since that is the level of leverage to which firms readjust when they recapitalize. This is consistent with the persistence on leverage ratios found in Lemmon et al. (2008).

\section{The Model}

We consider a firm whose instantaneous earnings before interest and taxes (EBIT), $\xi$, follow a geometric Brownian motion under the risk neutral pricing 
measure, i.e.,

$$
d \xi_{t}=\xi_{t} \mu d t+\xi_{t} \sigma d W_{t}
$$

with a given starting point, $\xi_{0}$. The constants $\mu$ and $\sigma$ are the drift and volatility of $\xi$, respectively, and $W$ is a standard Brownian motion. We can think of the origin of the EBIT process as the cash flow process generated by a production technology initially owned by an entrepreneur. The entrepreneur has the option to incorporate the firm (at a certain cost) based on the EBIT process by issuing debt and equity.

We assume that the firm can issue a single class of callable perpetual corporate debt with a fixed instantaneous coupon, $C$. The call feature of debt allows equity holders to better exploit the tax advantage to debt by increasing the amount of outstanding debt when earnings increase. This is an important feature to include in the model since it has a significant impact on optimal leverage as shown by Goldstein et al. (2001). Debt can only be increased by calling the existing debt and subsequently issuing new debt. ${ }^{1}$ Debt is called at a premium, and there is a cost of issuing new debt which is proportional to the principal.

The after-tax payment received by the debt holders on outstanding debt with coupon $C$ is $\left(1-\tau_{i}\right) C$, where $\tau_{i}$ is the rate of personal interest taxes paid by debt holders. Interest expenses are deductible before paying corporate taxes at the rate $\tau_{c}$. Hence, the amount available for dividends to equity holders is $\left(1-\tau_{c}\right)(\xi-C)$. The dividend tax rate is $\tau_{d}$ so the after-tax payment

\footnotetext{
${ }^{1}$ Otherwise, the equity holders have incentives to sequentially increase the outstanding debt by issuing new debt with the same seniority, and thereby diluting the existing debt. Of course, the debt holders rationally anticipate these incentives, see Leland (1994). Alternative new additional debt can be issued with lower priority as, for example, in Dockner et al. (2013) or Miltersen and Torous (2013).
} 
received by equity holders is $\left(1-\tau_{e}\right)(\xi-C)$, where $\tau_{e}=\tau_{c}+\left(1-\tau_{c}\right) \tau_{d}$. This assumes a symmetric tax refund if $\xi<C$. In practice, there is no tax refund for negative earnings, but there can be loss carry forwards. To mimic this friction, we assume the after-tax dividend received by equity holders is equal to $\left(1-\epsilon \tau_{e}\right)(\xi-C)$ for $\xi<C$, where $\epsilon \in[0,1]$ is the effective tax refund used when the earnings before taxes, $\mathrm{EBT}=\xi-C$, is negative.

We assume that there is a constant before tax riskless interest rate, $\hat{r}$. Since interest income is taxable, the discount rate used for pricing under the pricing measure is the after-tax riskless rate $r=\left(1-\tau_{i}\right) \hat{r}$. This reflects an assumption that not only is interest income taxed at the rate of $\tau_{i}$, but there is also a tax subsidy at the rate of $\tau_{i}$ associated with interest expenses. Hence, in terms of dynamic replication of contingent claims, the effective interest rate paid on the money market account used for borrowing in the replicating portfolio is $r$. We assume throughout that $\mu<r$ to ensure that the cash flows generated from the EBIT process have a finite market value.

In all cases considered below, the restructuring policy is parameterized by two boundaries: the renegotiation (or bankruptcy) boundary, $\underline{\xi}$, and the call boundary, $\bar{\xi}$. Obviously, $\xi<\xi_{0}<\bar{\xi}$. That is, when $\xi$ reaches the lower boundary, the debt is renegotiated (or the firm is declared bankrupt), and when $\xi$ reaches the upper boundary, the debt is called. These boundaries will be derived endogenously from the incentive compatibility constraints for the equity holders, and they depend on the mechanism used for renegotiation the firm's debt at the lower boundary. As a first step in solving the model, we take the boundaries and the pay-offs at the boundaries as exogenously given.

Debt and equity are time-homogeneous claims on the EBIT process, i.e., their values do not depend on calendar time. The payoffs depend only on the 
current level of EBIT, $\xi_{t}$, and the level of EBIT when the debt and equity were issued, $\xi_{s}, s \leq t$. Therefore, we denote the price at date $t$ of debt and equity issued at some prior date $s$ as $D\left(\xi_{t} ; \xi_{s}\right)$ and $E\left(\xi_{t} ; \xi_{s}\right)$, respectively. Implicitly, this means that the EBIT process $\left\{\xi_{u}\right\}_{u \in[s, t)}$ has stayed inside the interval $(\underline{\xi}, \bar{\xi})$ in the time period $[s, t)$.

We show in AppendixA that both the debt and equity price functions are positive homogeneous of degree one in $\left(\xi_{t}, \xi_{s}\right)$ (cf. equation (A.6) in AppendixA). That is,

$$
D\left(h \xi_{t} ; h \xi_{s}\right)=h D\left(\xi_{t} ; \xi_{s}\right)
$$

and

$$
E\left(h \xi_{t} ; h \xi_{s}\right)=h E\left(\xi_{t} ; \xi_{s}\right)
$$

for any $\xi_{t} \in[\underline{\xi}, \bar{\xi}]$ and $h>0$. Moreover, note that this homogeneity property implies that the restructuring policy $(\underline{\xi}, \bar{\xi})$ for each new issue of debt can be written as $\left(d \xi_{s}, u \xi_{s}\right)$ for some fixed positive constants $d<1$ and $u>1$.

Furthermore, for notational simplicity we write the initial values of debt and equity at the issue date as

$$
D\left(\xi_{s} ; \xi_{s}\right)=\xi_{s} D(1 ; 1)=D \xi_{s}
$$

and

$$
E\left(\xi_{s} ; \xi_{s}\right)=\xi_{s} E(1 ; 1)=E \xi_{s}
$$

where $D$ and $E$ are constants defined as $D=D(1 ; 1)$ and $E=E(1 ; 1)$.

We define the principal of the debt issued at date $s$ with a coupon rate $c^{*} \xi_{s}$ to be the initial value of the debt $D \xi_{s}$ (cf. Part 1 of Conjecture 1 in AppendixA). The debt is callable at a premium, $\lambda$, at any date $t \geq s$, 
i.e., the debt can be called (by the equity holders) at date $t$ by paying the debt holders $(1+\lambda) D \xi_{s}{ }^{2}$ When debt is issued, there are issuance costs, $k$, proportional to the par value of the debt. ${ }^{3}$ Hence, the total proceeds to the entrepreneur at date $s$ for issuing both perpetual debt with a coupon rate $c^{*} \xi_{s}$ and equity is

$$
A\left(\xi_{s}\right)=E\left(\xi_{s} ; \xi_{s}\right)+(1-k) D\left(\xi_{s} ; \xi_{s}\right)=\xi_{s}(E(1 ; 1)+(1-k) D(1 ; 1))=A \xi_{s}
$$

where $A$ is a constant defined as

$$
A=E(1 ; 1)+(1-k) D(1 ; 1)=E+(1-k) D .
$$

For simplicity, assume debt is issued at date zero when the EBIT process is initiated at $\xi_{0}$. We first look at boundary conditions at the upper boundary. When the EBIT process $\xi$ hits $u \xi_{0}$, the old debt is called at a premium, $\lambda$, and new debt is issued with a higher coupon to obtain an increased tax shield. That is, we have the following values of debt and equity at the call boundary, $u \xi_{0}$,

$$
\begin{aligned}
D\left(u \xi_{0} ; \xi_{0}\right) & =(1+\lambda) D\left(\xi_{0} ; \xi_{0}\right) \\
& =(1+\lambda) D \xi_{0}
\end{aligned}
$$

and

$$
\begin{aligned}
E\left(u \xi_{0} ; \xi_{0}\right) & =E\left(u \xi_{0} ; u \xi_{0}\right)+(1-k) D\left(u \xi_{0} ; u \xi_{0}\right)-(1+\lambda) D\left(\xi_{0} ; \xi_{0}\right) \\
& =(A u-(1+\lambda) D) \xi_{0} .
\end{aligned}
$$

These equations are the value-matching conditions at the upper boundary $u \xi_{0}$.

\footnotetext{
${ }^{2}$ Fischer et al. (1989b) and Flor and Lester (2002) study the ex-ante optimal size of the call premium.

${ }^{3}$ These costs remove the equity holders' incentive to restructure the debt continuously when there is no call premium, i.e. when $\lambda=0$, see footnote 1 .
} 


\subsection{Liquidation at the Lower Boundary}

The key feature of our model is the renegotiation game at the lower boundary. To be able to solve this model, we need as an intermediate step to compute the value of the firm when there is no possibility of renegotiation at the lower boundary $d \xi_{0}$. So that the debt holders' response to equity holders withholding coupons is immediate liquidation. The claim to the EBIT process is then acquired as a going concern by a new entrepreneur who again can optimally lever the firm. A fraction, $\alpha$, of the proceeds covers the bankruptcy costs. The net proceeds go first to the debt holders to cover their original principal, and if there is a surplus, it goes to the equity holders. This is in accordance with the absolute priority rule. However, because the equity holders have limited liability, the debt holders are in most cases not able to recover their full principal. This happens when the proceeds from the sale of assets less the bankruptcy costs are smaller than the original principal. Hence, we get the following value-matching conditions at $d \xi_{0}$ :

$$
\begin{aligned}
D\left(d \xi_{0} ; \xi_{0}\right) & =\min \left\{(1-\alpha) A\left(d \xi_{0}\right), D\left(\xi_{0} ; \xi_{0}\right)\right\} \\
& =\min \{(1-\alpha) A d, D\} \xi_{0},
\end{aligned}
$$

and

$$
\begin{aligned}
E\left(d \xi_{0} ; \xi_{0}\right) & =\max \left\{(1-\alpha) A\left(d \xi_{0}\right)-D\left(\xi_{0} ; \xi_{0}\right), 0\right\} \\
& =\max \{(1-\alpha) A d-D, 0\} \xi_{0}
\end{aligned}
$$

With these assumptions, we are able to price debt and equity for exogenously given boundaries by solving a fixed-point problem for the two unknowns $E(1,1)$ and $D(1,1)$.

We next take into account that the equity holders control the firm and decide (i) when to call the debt and (ii) at each instant in time whether to pay the coupons to the debt holders or not. That is, the incentives of the 
equity holders endogenously determine the restructuring policy, and both equity and debt holders rationally anticipate these incentives already at debt issuance. The equity holders find it optimal to call the debt at $u \xi_{0}$ when the following condition is fulfilled:

$$
\frac{\partial}{\partial \xi} E\left(u \xi_{0} ; \xi_{0}\right)=A
$$

where the partial derivative is with respect to the first argument of the equity price function $\left(\xi, \xi_{0}\right) \mapsto E\left(\xi, \xi_{0}\right)$. This condition is the smooth-pasting condition at the upper boundary $u \xi_{0} \cdot{ }^{4}$

Similarly, the equity holders find it optimal to declare bankruptcy at $d \xi_{0}$ (by withholding the coupons) when the following smooth-pasting condition is fulfilled:

$$
\frac{\partial}{\partial \xi} E\left(d \xi_{0} ; \xi_{0}\right)=(1-\alpha) A 1_{\{(1-\alpha) A d \geq D\}},
$$

where $1_{\mathcal{E}}$ is the indicator function for the event $\mathcal{E}$.

Given the coupon rate $C=c \xi_{0}$, AppendixB shows how the value-matching and smooth-pasting conditions determine the debt and equity price functions. In particular, for $\xi=1$ we get the constants $E$ and $D$. Since the optimally levered firm value, $A=E+(1-k) D$, is used in the boundary conditions stated above, the derivation of the equity and debt prices (and the optimal boundaries) is actually still a fixed-point problem. Recall that $E$ and $D$ are determined for a given coupon rate. In order to determine the optimally levered firm value, we must (numerically) optimize over the coupon rate $c$.

\footnotetext{
4 This (or similar) smooth-pasting or high-contact conditions are used throughout the literature, see, e.g., Merton (1973); Leland (1994); Mella-Barral (1999). Merton, footnote 60 gives an argument for the validity of this condition, but see also Dixit (1991), Dixit (1993), Brekke and Øksendal (1991), and Brekke and Øksendal (1994) for explanations of what type of optimality this condition leads to.
} 
With the optimal rate, $c^{*}$, the optimal capital structure policy of the firm is characterized by the constants $E, D, u, d$, and $c^{*}$.

Up to this point, our model is similar to that of Goldstein et al. (2001) but with one notable difference: Goldstein et al. (2001) assume that the firm's assets in bankruptcy are sold off at their unlevered value, which is equal to $\left(1-\tau_{e}\right) \xi /(r-\mu)$. Hence, the debt and equity values are known functions of $\xi$ at the lower boundary. In our base case model, the liquidation value of the firm at the lower boundary recognizes that the assets of the firm can subsequently be optimally levered, i.e., the tax advantage to debt is not lost at bankruptcy. Hence, our model leads to a fixed-point problem when solving for the initial values of debt and equity due to the optimally levered firm value both at the lower boundary and the call boundary. A similar fixedpoint problem due to restructuring at the call boundary has been studied in Kane et al. (1985), Fischer et al. (1989a), and Goldstein et al. (2001).

\subsection{Debt Renegotiation with Credible Threats}

The going concern value of the firm is always larger than the value after bankruptcy and, therefore, it is in the best interest of debt and equity holders to avoid bankruptcy at the lower boundary. While one could easily add other frictions that would make bankruptcy optimal in some cases, we focus on the outcome of debt renegotiation. In most strategic debt service models, equity holders make take-it-or-leave-it offers to the debt holders that just leave the debt holders as well off as in a bankruptcy. Hence, equity holders get the entire benefit of the saved bankruptcy costs. The problem with these debt renegotiation models is that it is not obvious that the equity holders' threat of withholding the coupons, if the debt holders reject the restructuring proposal, is a credible threat. In fact, it almost never is in these models. If the debt holders declare the firm bankrupt, the equity holders would in most cases get 
nothing. ${ }^{5}$ Thus, if the equity holders' restructuring proposal is rejected by the debt holders, they might prefer to continue paying the original coupon, and thereby avoid bankruptcy.

In our model, the equity holders' proposal takes into account that acceptance by the debt holders depends on their conjecture of the equity holders' rational response to a rejection. Equity holders may decide to continue paying coupons, but nothing prevents them from immediately proposing a new restructuring. To close the model, we must introduce a friction leaving the firm in a different state after a rejected renegotiation proposal so that an identical restructuring proposal is not immediately proposed. The friction we introduce is that the equity holders are only allowed to make a finite number of renegotiation proposals. If there are no more renegotiation options, we end up in the model of the preceding section in which the only response to equity withholding coupons is liquidation. The finite number of renegotiation options implies that after a rejection, the firm is in a different shape than it was before the proposal was presented. That is, the firm has moved one step closer to a world with no possibility of restructuring.

The model is most easily understood in the case of one remaining renegotiation option, and we therefore consider this case in detail in what follows. For this we need additional notation. We use a subscript to denote the number of remaining options. Thus, for example, $E_{0}(1,1)$ now denotes the value of equity in the model of the previous subsection, i.e., the value of equity after we have taken into account the optimal call policy and the optimal liquidation policy of the equity holders, and where the coupon has been chosen

\footnotetext{
${ }^{5}$ If the proposal is made for a very high level of EBIT it is possible that the default value of the firm is higher than the initial debt holders' principal. This would leave some value for equity holders.
} 
to optimize firm value. Similarly, $E_{0}(\xi, 1)$ denotes the value of equity when the EBIT process has moved to $\xi$, but the capital structure and policies are those determined when $\xi$ was equal to 1 .

Consider now the renegotiation game at the lower boundary, $d \xi_{0}$, at which the equity holders make their restructuring proposal, which is their last remaining proposal. Let $E_{1}^{c}$ denote the value of equity with one remaining option based on the assumption that the restructuring proposal is rejected and that the equity holders continue to pay the original coupon $c_{1}$ (which at this point is not to be thought of as chosen optimally). We can express the value of continuing with the existing coupon using the function $E_{0}$ which presumes an optimal coupon of $c_{0}^{*}$. To see this, note that paying the coupon $c_{1}$ would be optimal if the firm had been capitalized with zero remaining options at the starting point $c_{1} / c_{0}^{*} .{ }^{6}$ We can therefore express the value of equity with zero remaining options and coupon $c_{1}$ as $E_{0}\left(d \xi_{0}, c_{1} / c_{0}^{*}\right)$, which captures the fact that equity will choose the optimal boundaries given the coupon $c_{1}$, but also that EBIT is now at $d \xi_{0}$. In other words, the value of

\footnotetext{
${ }^{6}$ This procedure of re-adjusting the initial level of the EBIT, $\xi_{0}$, in order to properly account for equity holders' optimal behavior with zero renegotiation options does have a small issue in that the value we use for the debt principal with no renegotiation options left may not be the same as was the case with one renegotiation options left even though the coupon rate is right. However, this is only a minor inexactitude of our numerical procedure for two reasons. (i) The principal will only play a role if either (a) the debt is called or (b) if the firm is liquidated and the acquisition value of the firm net of bankruptcy costs is higher than the principal. When the firm is in financial distress neither (a) nor (b) is the case and therefore the value of the debt is fairly insensitive to the exact size of the principal of the debt. (ii) When we increase the number of options, our numerical calculations show that the principal does approach the right size.
} 
equity when choosing to continue paying the existing coupon is

$$
E_{1}^{c}=E_{0}\left(d \xi_{0} ; c_{1} / c_{0}^{*}\right)
$$

On the other hand, if the restructuring proposal is rejected and the equity holders withhold the coupon payments, then the firm is declared bankrupt (because we are then in the case with zero renegotiation options). This means that the equity value based on the assumption that a rejection is followed by liquidation is

$$
E_{1}^{b}=\max \left\{(1-\alpha) A_{0} d-D_{1}, 0\right\} \xi_{0} .
$$

Since the firm's going concern value in liquidation, $A_{0}$, includes no options to renegotiate. The choice of whether to continue to pay the original coupon rate or to declare bankruptcy is in the hands of the equity holders. Hence, the equity value, assuming that the proposal leads to rejection, is the maximum of the two alternatives, i.e.,

$$
E_{1}^{r}=\max \left\{E_{1}^{c}, E_{1}^{b}\right\}
$$

This value depends solely on values we know from solving the case with zero renegotiation options. The corresponding debt value depends on the choice of the equity holders. If the equity holders continue to pay the original coupon, the debt value is

$$
D_{1}^{c}=D_{0}\left(d \xi_{0} ; c_{1} / c_{0}^{*}\right) .
$$

In this case, the debt holders are not in a position to force bankruptcy. On the other hand, if the equity holders cease the coupon payments, the debt holders immediately declare bankruptcy. The bankruptcy value of debt is

$$
D_{1}^{b}=\min \left\{(1-\alpha) A_{0} d, D_{1}\right\} \xi_{0}
$$

If the debt holders reject the restructuring proposal, the value of debt is

$$
D_{1}^{r}=D_{1}^{c} 1_{\left\{E_{1}^{c} \geq E_{1}^{b}\right\}}+D_{1}^{b} 1_{\left\{E_{1}^{c}<E_{1}^{b}\right\}} .
$$


This is our assumption of credible threats. Debt holders rationally anticipate whether upon a rejection it is in the interest of equity holders to continue with the existing coupons or to liquidate. All values on the right hand side are available from the case with zero renegotiation options.

Suppose instead the proposal is accepted. Then the joint value of debt and equity is the optimally levered firm value, but now with no remaining options to renegotiate, i.e,

$$
E_{1}^{a}\left(d \xi_{0} ; \xi_{0}\right)+D_{1}^{a}\left(d \xi_{0} ; \xi_{0}\right)=A_{0} d \xi_{0}
$$

Hence, the joint gain from acceptance of the proposal is

$$
R_{1}=A_{0} d \xi_{0}-\left(E_{1}^{r}+D_{1}^{r}\right)
$$

This gain is based on the rational response of equity holders to a rejection of their proposal. This gain is not computed using a potentially non-credible threat of liquidation as the only alternative. Rather, it is a gain compared to the optimal response by equity holders to a rejection. We assume that the equity holders' bargaining power is exogenously given by $\gamma \in[0,1]$. That is, the equity holders' restructuring proposal is such that they get the fraction $\gamma$ of the restructuring gain. Hence, we can write the value-matching conditions at the lower boundary, $d \xi_{0}$, as

$$
E_{1}\left(d \xi_{0} ; \xi_{0}\right)=\gamma R_{1}+E_{1}^{r}
$$

and

$$
D_{1}\left(d \xi_{0} ; \xi_{0}\right)=(1-\gamma) R_{1}+D_{1}^{r}
$$

Clearly, the equity holders will not propose a restructuring unless the restructuring gain is non-negative. ${ }^{7}$ Hence, the specification of the renegotiation

\footnotetext{
${ }^{7}$ If $\gamma=0$, we impose the constraint $R \geq 0$.
} 
mechanism ensures that the debt holders accept the restructuring proposal. This follows from the fact that both parties get a value which is at least as high as the value they would get if the debt restructuring proposal is rejected. The corresponding smooth-pasting condition at the renegotiation boundary $d_{1} \xi_{0}$ is

$$
\frac{\partial}{\partial \xi} E_{1}\left(d_{1} \xi_{0} ; \xi_{0}\right)=\left.\frac{\partial}{\partial \xi}\left(\gamma R_{1}+E_{1}^{r}\right)\right|_{\xi=d_{1} \xi_{0}} .
$$

At the call boundary, $u_{1} \xi_{0}$, the value-matching and smooth-pasting conditions are equivalent to those used in the previous sections. Thus, the valuematching conditions are

$$
D_{1}\left(u_{1} \xi_{0} ; \xi_{0}\right)=(1+\lambda) D_{1}\left(\xi_{0} ; \xi_{0}\right)=(1+\lambda) D_{1} \xi_{0}
$$

and

$$
E_{1}\left(u_{1} \xi_{0} ; \xi_{0}\right)=\left(A_{1} u_{1}-(1+\lambda) D_{1}\right) \xi_{0}
$$

where

$$
A_{1}=E_{1}(1 ; 1)+(1-k) D_{1}(1 ; 1) .
$$

Note that the optimally levered firm value, $A_{1}$, in the equity holders' valuematching condition (17) reflects an assumption that renegotiation options are not lost after a call. Moreover, the optimal call boundary fulfills the following smooth-pasting condition:

$$
\frac{\partial}{\partial \xi} E_{1}\left(u_{1} \xi_{0} ; \xi_{0}\right)=A_{1}
$$

Once we have established the optimal boundaries, we can optimize over the initial coupon $c_{1}$.

Let $n$ denote the number of remaining renegotiation options. The procedure for solving the model with one renegotiation option can now be summarized as follows: When there are no renegotiation options left, i.e., $n=0$, the 
only possibility at the lower boundary is to declare bankruptcy. In our augmented notation, we characterize the solutions to this model by the constants $E_{0}, D_{0}, u_{0}, d_{0}$, and $c_{0}^{*}$. Given these constants, we determine the debt and equity values in the last debt renegotiation game as follows. If the proposal is accepted, the optimally levered firm value is $A_{0} d_{1} \xi_{s}=\left(E_{0}+(1-k) D_{0}\right) d_{1} \xi_{s}{ }^{8}$ On the other hand, suppose the proposal is rejected and it is optimal for the equity holders to continue paying the existing coupons. In this case, the rejection values of debt and equity are determined by the solution of the model with $n=0$, but using the existing coupon. Thus, we can solve for the optimal capital structure policy assuming there is one remaining renegotiation option. The policy is characterized by the constants $E_{1}, D_{1}, u_{1}, d_{1}$, and $c_{1}^{*}$. This backward induction procedure can now be continued to the case of $n$ remaining options by solving for $E_{n}, D_{n}, u_{n}, d_{n}$, and $c_{n}^{*}$ in terms of $E_{n-1}, D_{n-1}, u_{n-1}, d_{n-1}$, and $c_{n-1}^{*}$. This completes the description of the solution procedure for the equilibrium debt renegotiation model with $n$ renegotiation options. ${ }^{9}$

\section{The Impact of Debt Renegotiation and Credible Threats}

[Table 1 about here.]

[Figure 1 about here.]

\footnotetext{
${ }^{8}$ Here, $\xi_{s}$ denotes the level of EBIT at the last restructuring date, when the existing capital structure was fixed. Thus, the current EBIT is $\xi=d_{1} \xi_{s}$.

${ }^{9} \mathrm{~A}$ similar solution procedure is proposed by Øksendal and Sulem (2005, Chapter 7) as a method to approximate the solution to an impulse control problem by solving a series of iterated optimal stopping time problems. Moreover, Øksendal and Sulem (2005) show that the proposed solution procedure leads to a solution for the optimal value function and controls of the problem. In our setting, this corresponds to finding the optimally levered firm value and the optimal restructuring policies.
} 
We first explain the qualitative effects of having one renegotiation option insisting that the renegotiation is based on credible threats. The effect is best understood if we let all the bargaining power reside with equity holders, i.e., we set $\gamma=1$. All other input parameters are given in Table 1. We focus at the value functions near the optimal renegotiation boundary. Figure 1 depicts the optimally levered firm value with zero remaining renegotiation options $\left(A_{0} \xi\right)$. We also show the liquidation value $\left((1-\alpha) A_{0} \xi\right)$. For all values of EBIT above the optimal renegotiation boundary $\left(\xi=d_{1} \xi_{0}=0.272\right)$, equity holders prefer to continue with the existing coupon rather than to liquidate the firm (i.e., $E_{1}^{c}>E_{1}^{b}$ ). Since debt holders know it is in the best interest of equity holders to continue servicing the debt with zero remaining options, they will reject renegotiation proposals, based on a liquidation threat, made when $\xi>d_{1} \xi_{0}$. Hence, equity holders optimally postpone their renegotiation offer to the point at which liquidation becomes a credible threat (i.e., $\xi=$ $d_{1} \xi_{0}$. In this way, they maximize the value of their remaining renegotiation option. As a consequence, the debt value $\left(D_{1}\right.$ and also $\left.D_{1}^{c}\right)$ is larger than the liquidation value for values of $\xi$ above, but close to, the restructuring boundary $d_{1} \xi_{0}$. This is what separates our model based on credible threats from a model in which the threat of liquidation is not necessarily credible. In a strategic debt service model based on non-credible liquidation threats, the debt renegotiation offer may be proposed at a higher level of $\xi$ than $d_{1} \xi_{0}$. This implies that in these models, the debt value is always lower than the liquidation value.

[Figure 2 about here.]

How large, then, are the quantitative effects of debt renegotiation backed by credible threats? Figure 2 depicts the debt and equity values as well as 
the optimal coupon and the renegotiation and call boundaries as a function of the number of renegotiation options. The optimal coupon, the optimal leverage, and the optimally levered firm value all increase significantly going from a setting with liquidation at the lower boundary $(n=0)$ to a setting with one renegotiation option $(n=1)$. Further increasing the number of renegotiation options has only a minor effect on all relevant quantities. The ex-ante value of the increased leverage can be measured by the dollar tax advantage to debt (TAD) defined as the difference between the optimally levered firm value and the unlevered firm value. TAD increases from 2.04 with $n=0$ to 2.83 with $n=1$ and 3.06 with $n=8$. Hence, the possibility of debt renegotiation increases TAD by $50 \%$ even when debt renegotiation proposals must be backed by credible threats.

Trade-off models with costs of calling and issuing debt tend to have wide boundaries within which EBIT can fluctuate before the firm's capital structure is re-optimized. In our base case, the lower renegotiation boundary is at $27 \%$ of initial EBIT and debt is called when EBIT has increased by a factor of approximately 2.5. These boundaries narrow only slightly when the number of renegotiation options increases. Therefore, the important caveat of Strebulaev (2007) applies, i.e., cross-sectional analysis of leverage ratios, which do not recognize that firms are away from their optimal leverage most of the time, may not be consistent with our predictions.

\section{Implications for Capital Structure and APR violations}

[Figure 3 about here.]

In Figure 3 we examine the impact of changing the equity holders' bargaining power, $\gamma$, which determines the distribution of the renegotiation gain between equity holders and debt holders. We leave all other parameters as 
they are in the base case, cf. Table 1, and we focus on the setting with "many" renegotiation offers $(n=8)$. Interestingly, the bargaining power has only a limited impact on the optimally levered firm value. Optimal leverage decreases somewhat with $\gamma$, cf. Panel 3a, but the bargaining power has a significant influence on absolute priority (APR) violations (defined as the fraction of the firm value that is allocated to equity at the time of renegotiation), cf. Panel 3b. Lowering the equity holders' bargaining power from one down to zero reduces the size of the absolute priority violation virtually linearly down to zero as well. When the firm's capital structure is optimized, the objective is total firm value maximization. Therefore, it is not a firstorder effect how equity holders and debt holders eventually share the firm value at each renegotiation. Consequently, the optimally levered firm value does not vary with the equity holders' bargaining power, $\gamma$. On the other hand, equity holders postpone their renegotiation proposal until the threat of liquidation becomes credible and, hence, at each round of renegotiations equity holders get a fraction, $\gamma$ of the saved bankruptcy costs.

Note from Panel 3c that the recovery rate of debt in renegotiation (defined as the fraction of debt principal received by debt holders at the time of renegotiation) is relatively unaffected by the equity holders' bargaining power. This is because the bargaining power only determines the allocation of the renegotiation gains, i.e., debt holders get the liquidation value of the firm plus their fraction of the renegotiation gain.

Empirical research reveals that APR violations are common, but recent evidence also points to the fact that violations have become less frequent and of smaller magnitude. In the 1980s, APR violations occur as often as in $75 \%$ of the U.S. Chapter 11 cases and equity received on average $7.6 \%$ of the reorganized firm's value, see Franks and Torous (1989), Franks and Torous 
(1994), Eberhart et al. (1990a), Weiss (1990), and Betker (1995). Within the last decade, however, Bharath et al. (2010) report that the empirical evidence on APR violations has changed. In the period 1991-2005, the average frequency of violations decreased to $22 \%$. Also, the magnitude of absolute priority violations has declined from $10 \%$ of firm value to less than $2 \%$ of firm value. Bharath et al. (2010) suggest that these changes are due to Chapter 11 becoming more creditor friendly in recent years, e.g., due to increasing reliance on debtor-in-possession (DIP) financing. Similarly, Senbet and Wang (2010) point to the fact that there have been several innovations related to the bankruptcy reorganization process in recent years starting in the 1990s. The essence is that creditors have gained stronger bargaining power in the recent years at the expense of equity holders. While our model can only make the APR violations disappear by assigning zero bargaining power to equity holders - and therefore has less to say about the frequency of violations - it clearly implies that lowering the bargaining power lowers the size of the APR violations. Note also, that the size of the violation is still small relative to firm value, and therefore, the recovery value of debt is fairly insensitive to the bargaining power of equity holders. The strength of the position of creditors in a bankruptcy or renegotiation is often proxied by creditor dispersion, and we would therefore expect to see no significant effect of creditor dispersion on recovery values of debt. This is consistent with the evidence found in Acharya et al. (2007). In summary, the distribution of bargaining power, $\gamma$, has only a minor impact on the capital structure choice and on debt recovery, but it significantly affects the size of the APR violation.

[Figure 4 about here.]

Bankruptcy costs, $\alpha$, turn out to play a role similar to that of the bargaining power, $\gamma$. As we learn from Figure 4, bankruptcy costs have a limited impact 
on the choice of capital structure and debt recovery, but they do affect the size of the APR violation. Lowering the bankruptcy costs down to zero reduce the size of the absolute priority violation virtually linearly down to zero as well.

On the equilibrium path the firm's capital structure will be renegotiated $n$ times before bankruptcy may eventually occur. Hence, from an ex-ante perspective the present value of the bankruptcy costs are very small. On the other hand, off the equilibrium path, equity holders effectively threaten to declare immediate bankruptcy (in the sense that they wait to propose their renegotiation proposal until the threat of liquidation becomes credible) and, hence, at each round of renegotiations, equity holders get half (in general a share equal to $\gamma$ ) of the saved bankruptcy costs.

[Figure 5 about here.]

In Figure 5 we examine the impact of the volatility of EBIT. Volatility does not affect the size of the APR violations, and it has only a limited effect on debt recovery, again consistent with the empirical evidence found in Acharya et al. (2007). Unsurprisingly, a higher volatility increases the equity value, and it decreases the leverage and thereby the tax advantage to debt. Unreported results show that yield spreads increase, while the renegotiation boundary decrease in the volatility. These results are consistent with other dynamic capital structure models. In models with no debt renegotiation, the equity holders receive no value at the lower boundary and, hence, the equity holders' claim is like a call option. Thus, it is not surprising that a higher volatility lowers the bankruptcy boundary. Despite the fact that the equity holders get a positive value at the lower boundary with debt renegotiation, we see a similar phenomenon. That is, the equity holders postpone 
the debt renegotiation even though this reduces the equity value they can obtain as the outcome of a debt renegotiation. Similarly, as a consequence of the reduction in the debt renegotiation boundary, debt recovery decreases as a function of the volatility, but only to a limited extend since the principal of the debt also decreases.

\section{Conclusion}

In this paper we study a dynamic trade-off model of a firm's capital structure in which there is renegotiation of debt when the firm does poorly. A critical feature of our model is that debt holders reject renegotiation offers from equity holders which are not credible. Our model shows that violation of the absolute priority rule is an optimal outcome of the renegotiation process. Hence, violations of the absolute priority rule can arise with no other frictions than taxes and bankruptcy costs. We find that the equity holders' bargaining power and the bankruptcy costs affect the size of the absolute priority violation, but none of these two parameters have any major impact on the optimal capital structure of the firm. They also have very little impact on debt recovery. Earnings (and thereby asset) volatility, which has a significant impact on the optimal capital structure choice, has virtually no impact on the size of the violations of absolute priority. Our results are consistent with other trade-off models in that it predicts large variations in leverage before it becomes optimal for firms to realign their capital structure either by renegotiating their debt terms or by issuing new securities.

Our model does not capture why some firms end up continuing operation after a debt renegotiation while others end up being liquidated. In our model, the firm is always more valuable as a going concern than liquidated - and as such the possibility of renegotiation is a social improvement in the sense that 
it reduces the deadweight cost of bankruptcy. The model can be extended in at least two ways to include this feature. Either we can introduce an exogenously given probability that the debt and equity holders cannot reach an agreement of how to restructure the firm, or we can introduce a second state variable measuring the value of the firm's assets. In the latter case, the firm may be liquidated simply because the firm's assets are more valuable than the present value of the EBIT process optimally levered. For example, the assets may be used for some other purpose than generating the current EBIT. One attempt in this direction is Flor (2008).

\section{Acknowledgements}

The paper benefitted greatly from comments from the editors Itay Goldstein and Dirk Hackbarth as well as an anonymous referee. We are grateful for discussions at the Norwegian School of Economics and Business Administration, Copenhagen Business School, the EFA Doctoral Tutorial, the University of Vienna, the Norwegian School of Management, The Anderson School at UCLA, meetings of the Bachelier Finance Society, EFA, CEPR, and the Econometric Society. We are grateful to Peter Bossaerts, Michael Brennan, Bhagwan Chowdhry, Mark Garmaise, Mark Grinblatt, Matthias Kahl, Richard Roll, Eduardo Schwartz, and other seminar participants for valuable comments and suggestions. The authors gratefully acknowledge financial support of the Danish Social Science Research Council. Lando and Miltersen acknowledge support from the Center for Financial Frictions (FRIC), grant no. DNRF102. 
Acharya, V., Bharath, S., Srinivasan, A., 2007. Does industry-wide distress affect defaulted firms? evidence from creditor recoveries. Journal of Financial Economics 85, 787-821.

Altman, E. I., Hotchkiss, E., 2010. Corporate Financial Distress and Bankruptcy: Predict and Avoid Bankruptcy, Analyze and Invest in Distressed Debt, 3rd Edition. John Wiley \& Sons, Inc.

Anderson, R. W., Sundaresan, S., Spring 1996. Design and valuation of debt contracts. The Review of Financial Studies 9 (1), 37-68.

Annabi, A., Breton, M., François, P., 2010. Resolution of financial distress under chapter 11 . Working paper 10-48, CIRPÉE.

Betker, B. L., 1995. Management's incentives, equity's bargaining power, and deviations from absolute priority rule in chapter 11 bankruptcies. Journal of Business 68 (2), 161-183.

Bharath, S., Panchapegesan, V., Werner, I., 2010. The changing nature of chapter 11. Working paper, Ohio State University, Charles A. Dice Center for Research in Financial Economics.

Black, F., Cox, J., 1976. Valuing corporate securities: Some effects of bond indenture provisions. The Journal of Finance XXXI, 351-367.

Brekke, K. A., Øksendal, B., 1991. The high contact principle as a sufficiency condition for optimal stopping. In: Stochastic Models and Option Value. Elsevier Science Publishers, B. V., North-Holland, Amsterdam, The Netherlands, pp. 187-208.

Brekke, K. A., Øksendal, B., Jul. 1994. Optimal switching in an economic 
activity under uncertainty. SIAM Journal of Control and Optimization. 32 (4), 1021-1036.

Bris, A., Welch, I., Zhu, N., 2006. The costs of bankruptcy: Chapter 7 liquidation versus chapter 11 reorganization. The Journal of Finance 61 (3), $1253-1303$.

Broadie, M., Chernov, M., Sundaresan, S., 2007. Optimal debt and equity values in the presence of chapter 7 and chapter 11. The Journal of Finance $62(3), 1341-1377$.

Dixit, A., 1991. A simplified treatment of the theory of optimal regulation of brownian motion. Journal of Economic Dynamics and Control 15, 657-673.

Dixit, A. K., 1993. The Art of Smooth Pasting. Harwood Academic Publishers.

Dockner, E., Mæland, J., Miltersen, K. R., 2013. Interaction between dynamic financing and investments: The impact of industry structure. Working paper, Copenhagen Business School.

Eberhart, A., Moore, W., Roenfeldt, R., 1990a. Security pricing and deviations from the absolute priority rule in bankruptcy proceedings. The Journal of Finance XLV, 1457-1469.

Eberhart, A. C., Moore, W. T., Roenfeldt, R. L., Dec. 1990b. Security pricing and deviations from the absolute priority rule in bankruptcy proceedings. The Journal of Finance XLV (6), 1457-1469.

Fischer, E. O., Heinkel, R., Zechner, J., Mar. 1989a. Dynamic capital structure choice: Theory and tests. The Journal of Finance XLIV, 19-40. 
Fischer, E. O., Heinkel, R., Zechner, J., Dec. 1989b. Dynamic recapitalization policies and the role of call premia and issue discounts. Journal of Financial and Quantitative Analysis 24, 427-446.

Flor, C. R., Jul. 2008. Capital structure and assets: Effects of an implicit collateral. European Financial Management 14 (2), 347-373.

Flor, C. R., Lester, J., 2002. Debt maturity, callability, and dynamic capital structure. Working paper, Dept. of Business and Economics, University of Southern Denmark, Campusvej 55, 5230 Odense M, Denmark.

François, P., Morellec, E., 2004. Capital structure and asset prices: Some effects of bankruptcy procedures. Journal of Business 77, 387-411.

Franks, J., Torous, W., 1989. An empirical investigation of firms in reorganization. The Journal of Finance XLIV, 747-779.

Franks, J., Torous, W., 1994. A comparison of financial recontracting in distressed exchanges and chapter 11 reorganizations. Journal of Financial Economics 35 (3), 347-70.

Galai, D., Raviv, A., Wiener, Z., 2007. Liquidation triggers and the valuation of debt and equity. Journal of Banking and Finance 31, 3604-3620.

Gilson, S., John, K., Lang, L., 1990. Troubled debt restructurings: An empirical study of private renegotiation of firms in default. Journal of Financial Economics 27, 315-353.

Goldstein, R., Ju, N., Leland, H. E., 2001. An ebit-based model of dynamic capital structure. Journal of Business 74 (4), 483-512. 
Hackbarth, D., Hennessy, C. A., Leland, H. E., Sep. 2007. Can the tradeoff theory explain debt structure? The Review of Financial Studies 20 (5), 1389-1428.

Hege, U., Mella-Barral, P., 2005. Repeated dilution of diffusely held debt. Journal of Business 78 (3), 737-786.

Kane, A., Marcus, A. J., McDonald, R. L., Dec. 1985. Debt policy and the rate of return premium to leverage. Journal of Financial and Quantitative Analysis 20 (4), 479-499.

Leland, H. E., Sep. 1994. Corporate debt value, bond covenants, and optimal capital structure. The Journal of Finance XLIX (4), 1213-1252.

Lemmon, M. L., Roberts, M. R., Zender, J. F., 2008. Back to the beginning: Persistence and the cross-section of corporate capital structure. The Journal of Finance 63, 1575-1608.

Mella-Barral, P., Fall 1999. The dynamics of default and debt reorganization. The Review of Financial Studies 12 (3), 535-578.

Mella-Barral, P., Perraudin, W. R. M., Jun. 1997. Strategic debt service. The Journal of Finance LII, 531-556.

Merton, R. C., Spring 1973. Theory of rational option pricing. Bell Journal of Economics and Management Science 4, 141-183, reprinted in (Merton, 1990, Chapter 8).

Merton, R. C., May 1974. On the pricing of corporate debt: The risk structure of interest rates. The Journal of Finance XXIX, 449-470.

Merton, R. C., 1990. Continuous-Time Finance. Basil Blackwell Inc., Padstow, Great Britain. 
Miltersen, K. R., Torous, W. N., 2013. Optimal maturity structure of risky corporate debt. Working paper, Copenhagen Business School.

Morse, D., Shaw, W., 1988. Investing in bankrupt firms. The Journal of Finance XLIII, 1193-1206.

Øksendal, B., Sulem, A., 2005. Applied Stochastic Control of Jump Diffusions. Springer-Verlag, Berlin Heidelberg, Germany.

Rubinstein, A., 1982. Perfect equilibrium in a bargaining model. Econometrica 50, 97-109.

Rubinstein, A., 1987. A sequential strategic theory of bargaining. In: Advances in Economic Theory: Fifth World Congress. Cambridge University Press, Cambridge, Great Britain, pp. 197-224.

Senbet, L. W., Wang, T. Y., 2010. Corporate financial distress and bankruptcy: A survey. Foundations and Trends in Finance 5 (4), 243-335.

Strebulaev, I. A., 2007. Do tests of capital structure theory mean what they say? The Journal of Finance 62 (4), 1747-1787.

Weiss, L. A., 1990. Bankruptcy resolution: Direct costs and violations of priority of claims. Journal of Financial Economics 27, 285-314. 


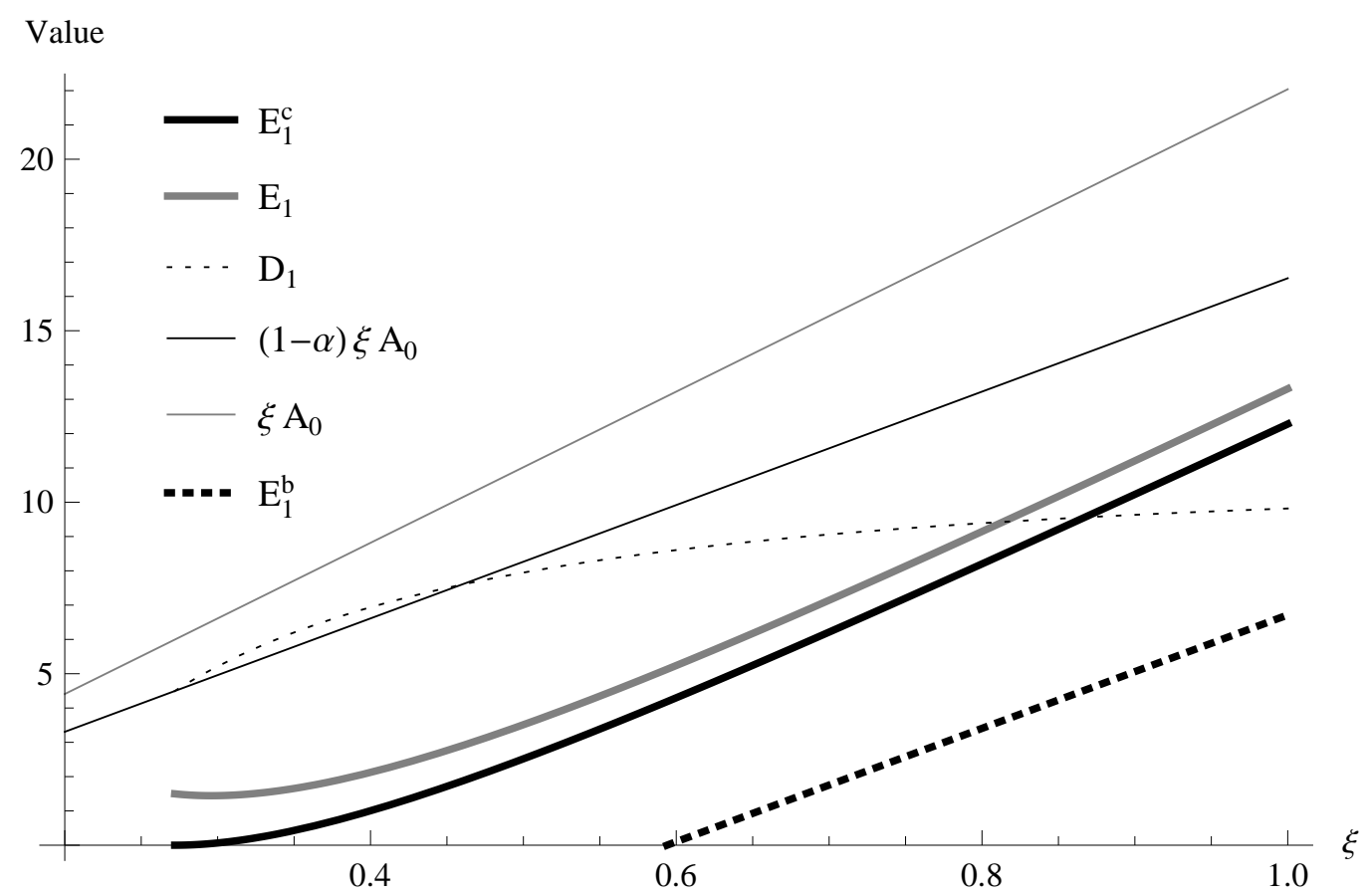

Figure 1: The value functions of the claims of the firm. The value functions are depicted as a function of the current EBIT value, $\xi$. The figure concentrates on the value functions for low values of EBIT between the lower renegotiation (or bankruptcy) boundary and the initial value, $\xi=1$. All parameters are as in the base case in Table 1, except that all the bargaining power reside with the equity holders, i.e., $\gamma=1$. $E_{1}$ is the equity value function with one renegotiation option left, $D_{1}$ is the debt value function with one renegotiation option left (since $\gamma=1$, this will also be the value of the debt if the renegotiation proposal is rejected and the equity holders decide to continue with the existing coupon, denoted $D_{1}^{c}$ in the text), $E_{1}^{c}$ and $E_{1}^{b}$ are the values of equity if their renegotiation proposal is rejected. $E_{1}^{c}$ is the value if equity holders decide to continue with the existing coupon and $E_{1}^{b}$ is the value if they declare immediate bankruptcy. $A_{0} \xi$ is the optimally levered firm value if the firm is restructured at $\xi$, and $(1-\alpha) A_{0} \xi$ is the optimally levered firm value after liquidation at $\xi$. 


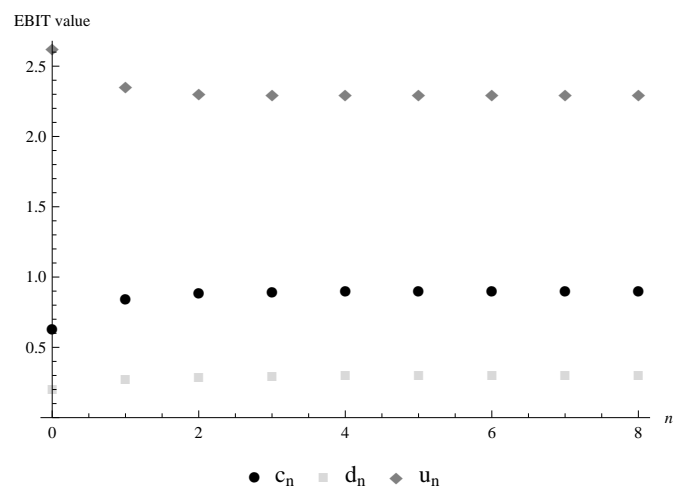

(a) Upper and lower restructuring boundaries, and the optimal coupon rate. $u_{n}$ is the upper restructuring boundary, $d_{n}$ is the lower renegotiation (or for $n=0$ bankruptcy) boundary, and $c_{n}$ is the optimal coupon.

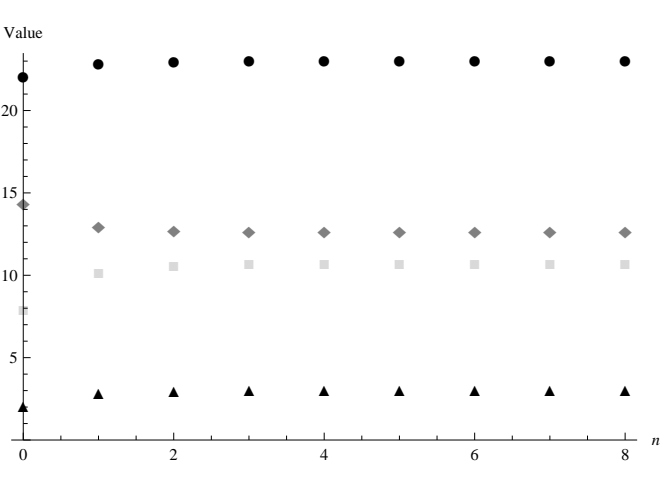

- $A_{n}=D_{n}, E_{n} \wedge T A D_{n}$

(b) $A_{n}$ is optimally levered firm value, $D_{n}$ is debt value, $E_{n}$ is equity value, and $\mathrm{TAD}_{n}$ is the tax advantage to debt.

Figure 2: Upper and lower restructuring boundaries, optimal coupon rate, and values of claims on the firm at the time when debt is issued and the firm's capital structure is optimized, i.e., when $\xi=1$. The values are depicted as a function of the number of renegotiation options, $n$. All other parameters are as in the base case in Table 1 . 


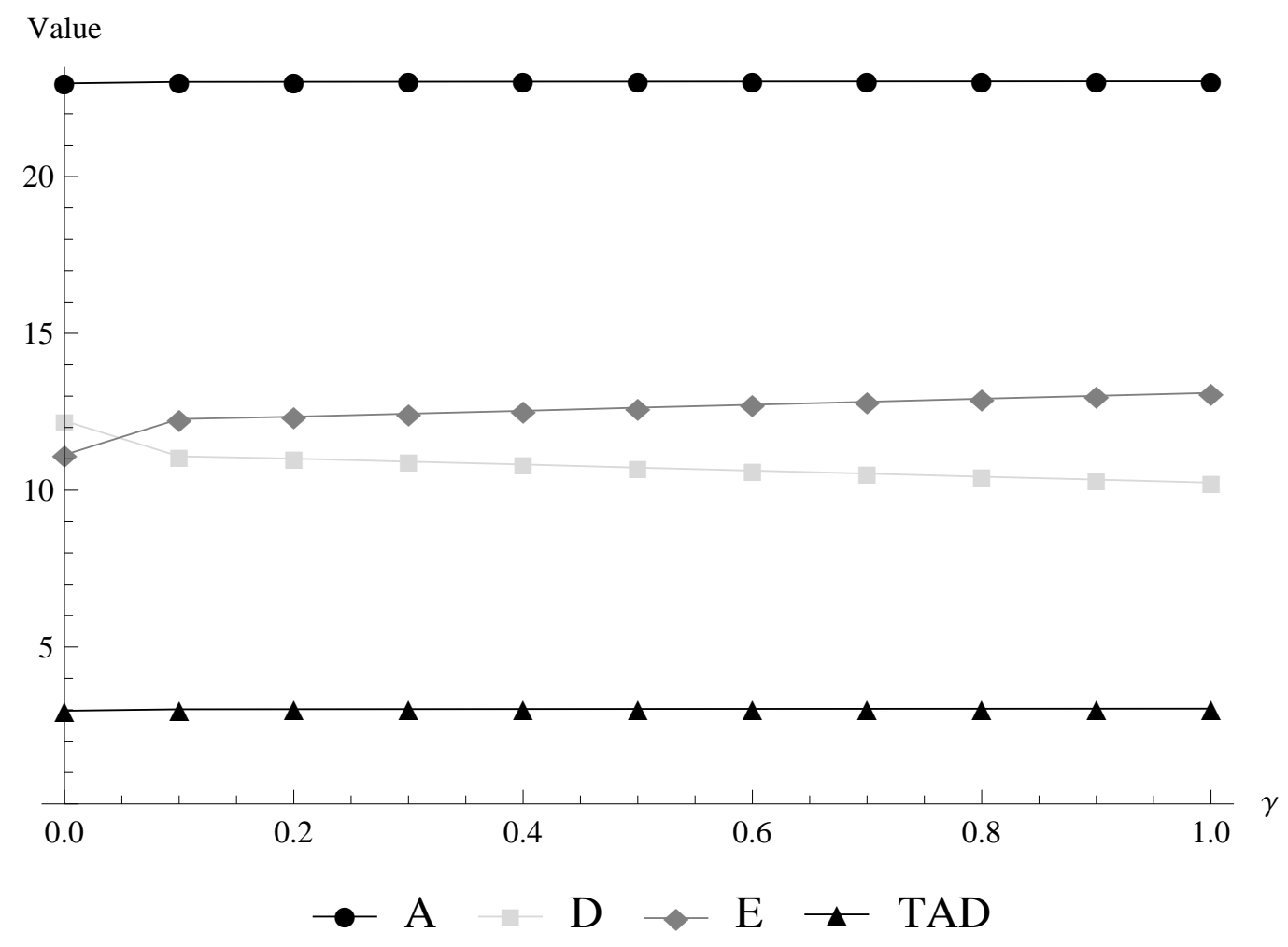

(a) $A$ is total firm value, $D$ is debt value, $E$ is equity value, and TAD is the tax advantage to debt at the time when debt is issued and the firm's capital structure is optimized, i.e., when $\xi=1$.

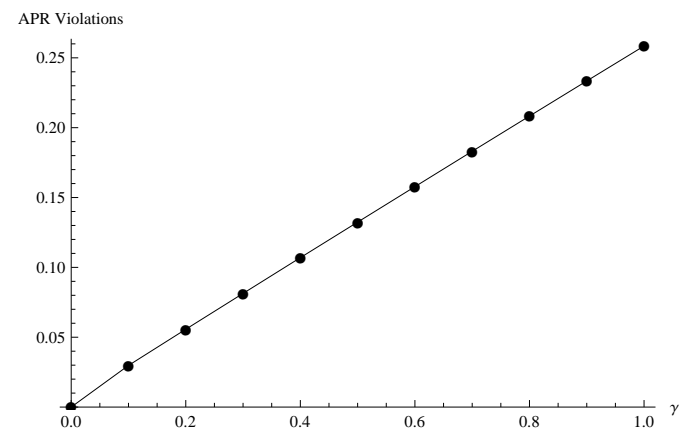

(b) The fraction of the firm value that is allocated to equity at the time of renegotiation, i.e., a measure of the APR violation.

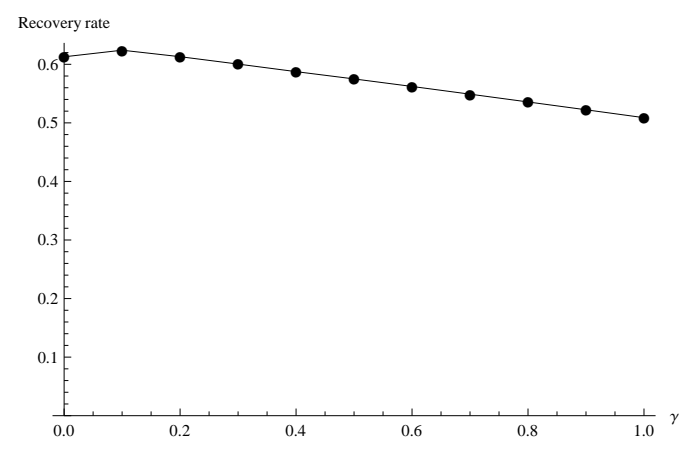

(c) The recovery rate of the debt (relative to principal) at the time of renegotiation.

Figure 3: Values of claims on the firm, APR violations, and debt recovery rates as a function of the bargaining power distribution between equity holders and debt holders, $\gamma$. All other parameters are as in the base case in Table 1. $\gamma=1$ means that the equity holders have all the bargaining power whereas $\gamma=0$ means that debt holders have all the bargaining power. 


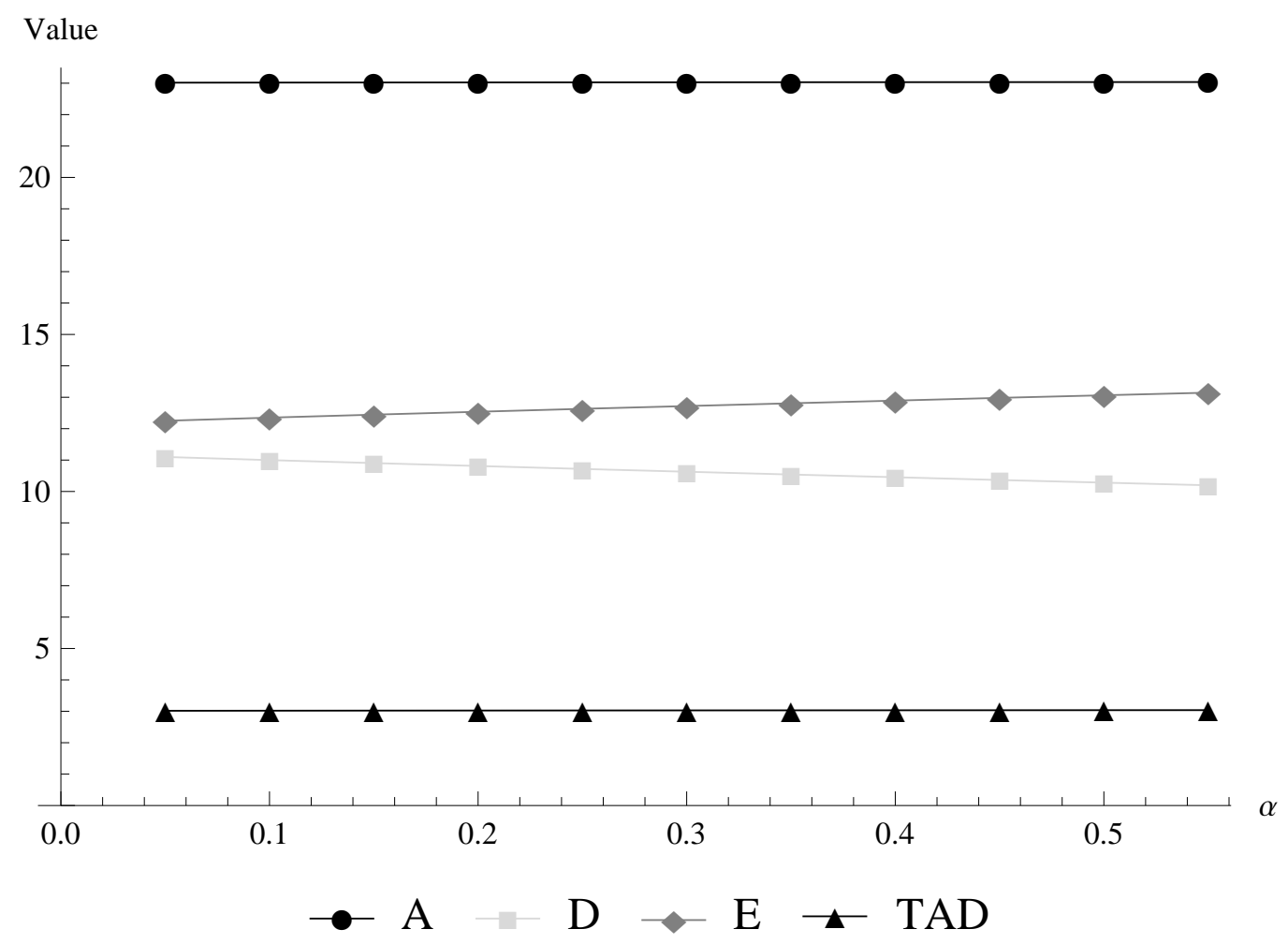

(a) $A$ is total firm value, $D$ is debt value, $E$ is equity value, and TAD is the tax advantage to debt at the time when debt is issued and the firm's capital structure is optimized, i.e., when $\xi=1$.

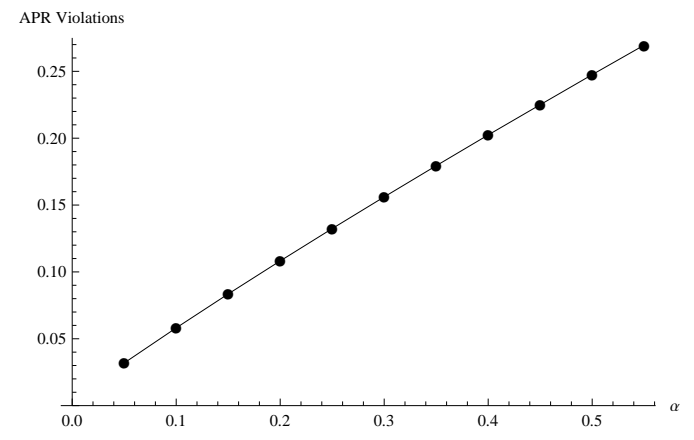

(b) The fraction of the firm value that is allocated to equity at the time of renegotiation, i.e., a measure of the APR violation.

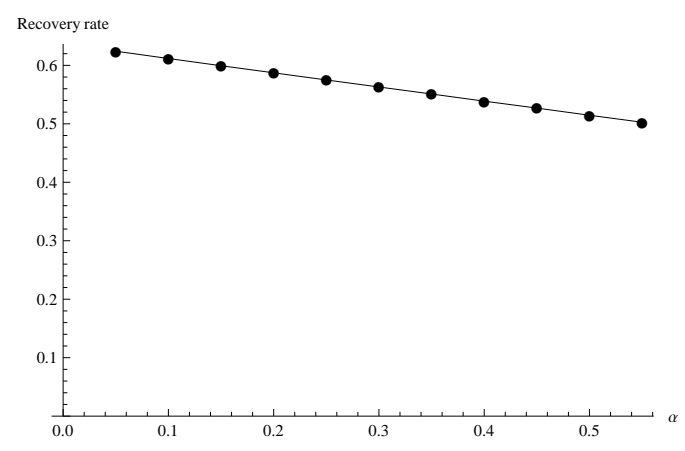

(c) The recovery rate of the debt (relative to principal) at the time of renegotiation.

Figure 4: Values of claims on the firm, APR violations, and debt recovery rates as a function of the bankruptcy costs, $\alpha$. All other parameters are as in the base case in Table 1. 


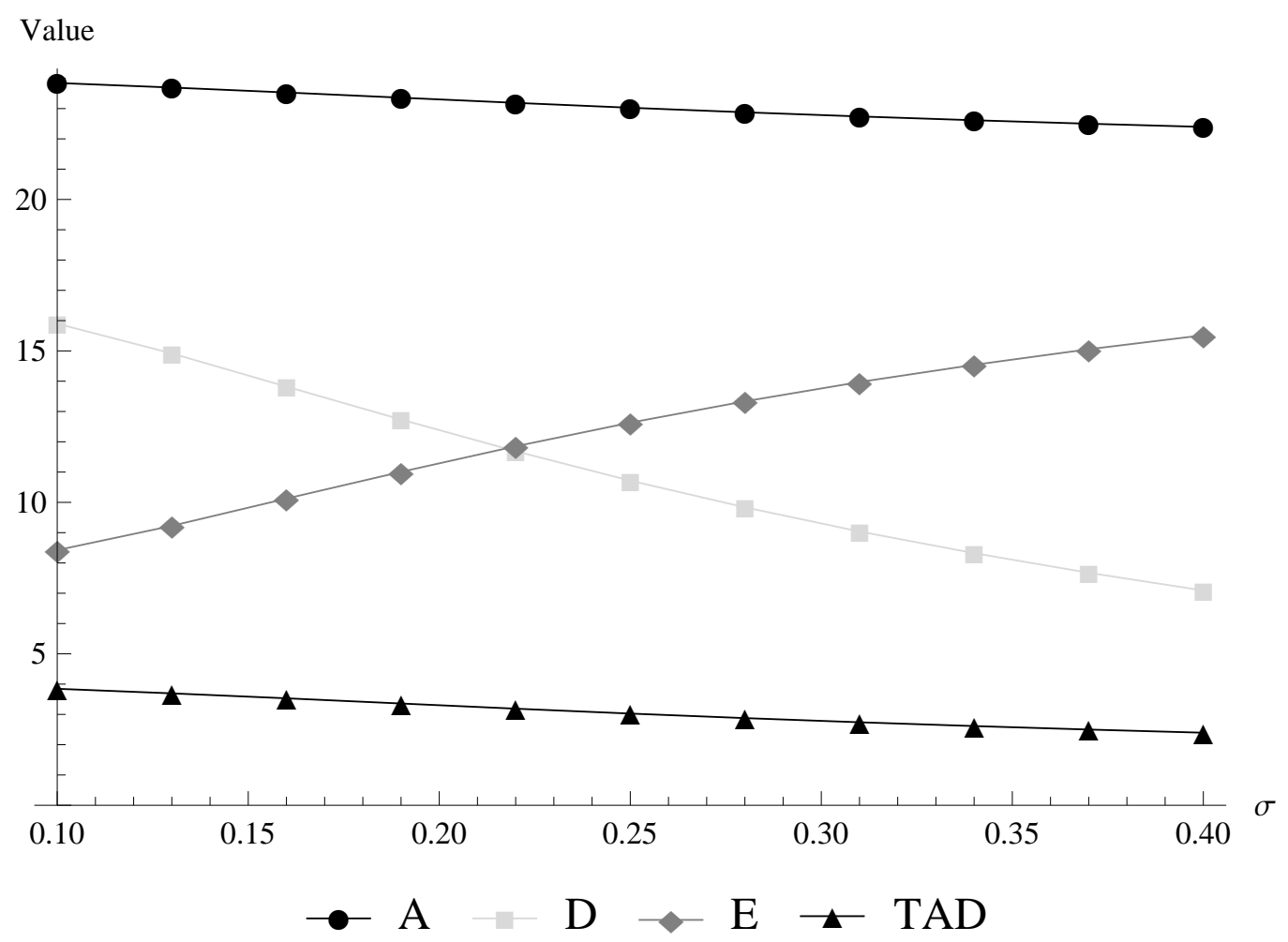

(a) $A$ is total firm value, $D$ is debt value, $E$ is equity value, and TAD is the tax advantage to debt at the time when debt is issued and the firm's capital structure is optimized, i.e., when $\xi=1$.

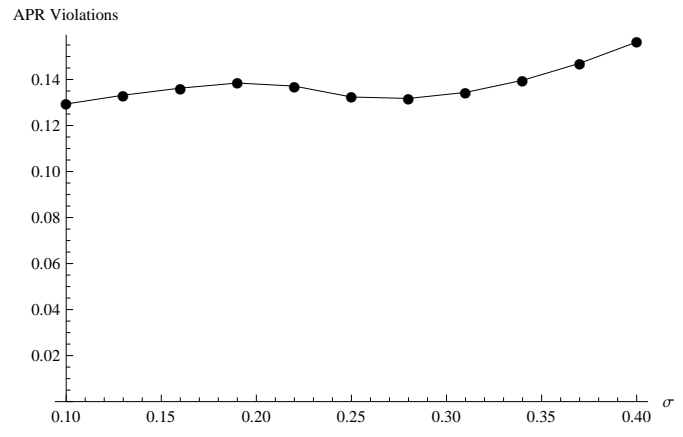

(b) The fraction of the firm value that is allocated to equity at the time of renegotiation, i.e., a measure of the APR violation.

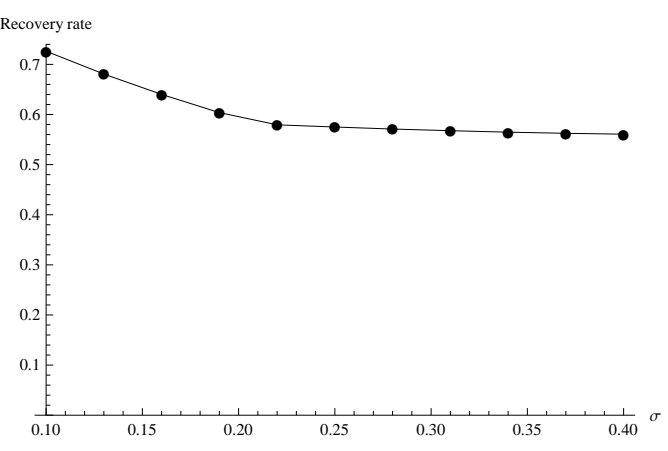

(c) The recovery rate of the debt (relative to principal) at the time of renegotiation.

Figure 5: Values of claims on the firm, APR violations, and debt recovery rates as a function of the EBIT volatility, $\sigma$. All other parameters are as in the base case in Table 1. 


\begin{tabular}{lcr}
\hline Risk neutral drift of the EBIT process & $\mu$ & $2 \%$ \\
Volatility of the EBIT process & $\sigma$ & $25 \%$ \\
After-tax riskless interest rate & $r$ & $4.5 \%$ \\
Tax rate on interest payments & $\tau_{i}$ & $35 \%$ \\
Effective tax rate on dividends & $\tau_{e}$ & $50 \%$ \\
Debt call premium & $\lambda$ & $5 \%$ \\
Bankruptcy costs & $\alpha$ & $25 \%$ \\
Issuing costs of new debt & $k$ & $3 \%$ \\
Equity holders' bargaining power & $\gamma$ & $50 \%$ \\
Effective tax refund & $\epsilon$ & $50 \%$ \\
\hline
\end{tabular}

Table 1: Base case parameter values. 


\section{AppendixA. Fixed Point Solution to the Pricing of Debt and Eq- uity (Online appendix)}

To set up some notation, we quickly reiterate parts of the standard theory. First, consider a very simple claim paying one unit of account when $\xi$ hits the lower boundary, $\underline{\xi}$, but only if the lower boundary has been hit before the upper boundary, $\bar{\xi}$. The price, denoted $\underline{P}$, of this claim as a function of the current level of EBIT, $\xi$, can be derived as

$$
\underline{P}(\xi)=\frac{-\bar{\xi}^{x_{2}} \xi^{x_{1}}+\bar{\xi}^{x_{1}} \xi^{x_{2}}}{\Sigma}, \quad \xi \in[\underline{\xi}, \bar{\xi}]
$$

where

$$
\begin{aligned}
& x_{1}=\frac{\left(\frac{1}{2} \sigma^{2}-\mu\right)+\sqrt{\left(\mu-\frac{1}{2} \sigma^{2}\right)^{2}+2 r \sigma^{2}}}{\sigma^{2}}, \\
& x_{2}=\frac{\left(\frac{1}{2} \sigma^{2}-\mu\right)-\sqrt{\left(\mu-\frac{1}{2} \sigma^{2}\right)^{2}+2 r \sigma^{2}}}{\sigma^{2}},
\end{aligned}
$$

and

$$
\Sigma=\bar{\xi}^{x_{1}} \underline{\xi}^{x_{2}}-\underline{\xi}^{x_{1}} \bar{\xi}^{x_{2}}
$$

This follows from the fact that $\underline{P}$ solves the linear ordinary differential equation (ODE)

$$
\frac{1}{2} \sigma^{2} \xi^{2} \underline{P}^{\prime \prime}(\xi)+\mu \xi \underline{P}^{\prime}(\xi)-r \underline{P}(\xi)=0,
$$

with the boundary conditions

$$
\underline{P}(\underline{\xi})=1 \quad \text { and } \quad \underline{P}(\bar{\xi})=0 .
$$

Similarly, interchanging the boundary conditions, we find the price of a claim paying one unit of account when $\xi$ hits the upper boundary, $\bar{\xi}$, but only if the upper boundary has been hit before the lower boundary, $\underline{\xi}$. The price, 
denoted $\bar{P}$, of this claim as a function of the current level of EBIT, $\xi$, can be derived as

$$
\bar{P}(\xi)=\frac{\xi^{x_{2}} \xi^{x_{1}}-\underline{\xi}^{x_{1}} \xi^{x_{2}}}{\Sigma}, \quad \xi \in[\underline{\xi}, \bar{\xi}] .
$$

We also need a claim that pays a dividend stream at the rate $\delta \xi_{s}+b$ at any date $s \in[t, \infty)$. The date $t$ value of this claim can easily be derived (either using risk neutral expectations or Gordon's formula) as

$$
\Delta \xi_{t}+B
$$

where

$$
\Delta=\frac{\delta}{r-\mu} \quad \text { and } \quad B=\frac{b}{r} .
$$

With these three claims priced we are able to price all claims of interest in our model. Consider the claim which pays off a dividend stream at the rate $\delta \xi_{t}+b$ at any date, $t$, until one of the boundaries has been hit. When it hits one of the boundaries, it pays out a final lump-sum payment. If the lower boundary, $\underline{\xi}$, has been hit first, it pays out $\underline{F}$, and if the upper boundary, $\bar{\xi}$, has been hit first, it pays out $\bar{F}$. The price, denoted $F(\cdot ; \delta, b, \underline{\xi}, \underline{F}, \bar{\xi}, \bar{F})$, of this claim as a function of the current level of EBIT, $\xi$, can easily be derived as

$F(\xi ; \delta, b, \underline{\xi}, \underline{F}, \bar{\xi}, \bar{F})=\Delta \xi+B+(\underline{F}-\Delta \underline{\xi}-B) \underline{P}(\xi)+(\bar{F}-\Delta \bar{\xi}-B) \bar{P}(\xi), \quad \xi \in[\underline{\xi}, \bar{\xi}]$.

Equation (A.2) has the following easy interpretation: The date $t$ value of getting the dividend stream at the rate $\delta \xi_{s}+b$ at any date $s \in[t, \infty)$ is $\Delta \xi_{t}+B$. Eventually $\xi$ will hit either $\underline{\xi}$ or $\bar{\xi}$. If, e.g., $\underline{\xi}$ has been hit first, the claim pays out $\underline{F}$ and the rest of the dividend stream (with a value of $\Delta \underline{\xi}+B$ ) is forgone. The net present value of this seen from date $t$ is $(\underline{F}-\Delta \underline{\xi}-B) \underline{P}\left(\xi_{t}\right)$. The same argument applies for the upper boundary, $\bar{\xi}$. 
Plugging in the definitions of $\underline{P}$ and $\bar{P}$ reveals ${ }^{10}$

$$
\begin{aligned}
F(\xi ; \delta, b, \underline{\xi}, \underline{F}, \bar{\xi}, \bar{F})= & \frac{1}{\Sigma}\left((\bar{F}-\Delta \bar{\xi}-B) \underline{\xi}^{x_{2}}-(\underline{F}-\Delta \underline{\xi}-B) \bar{\xi}^{x_{2}}\right) \xi^{x_{1}} \\
& +\frac{1}{\Sigma}\left((\underline{F}-\Delta \underline{\xi}-B) \bar{\xi}^{x_{1}}-(\bar{F}-\Delta \bar{\xi}-B) \underline{\xi}^{x_{1}}\right) \xi^{x_{2}} \\
& +\Delta \xi+B, \quad \xi \in[\underline{\xi}, \bar{\xi}] .
\end{aligned}
$$

A very useful property of the price function, $F$, is the following positive homogeneity of degree one property

$$
F(h \xi ; \delta, h b, h \underline{\xi}, h \underline{F}, h \bar{\xi}, h \bar{F})=h F(\xi ; \delta, b, \underline{\xi}, \underline{F}, \bar{\xi}, \bar{F})
$$

for any $\xi \in[\underline{\xi}, \bar{\xi}]$ and $h \in \mathbb{R}_{+}$. This is very easily checked by directly applying equation (A.5). ${ }^{11}$

\footnotetext{
${ }^{10}$ Alternatively, equation (A.5) can be derived by observing that $F$ is the solution to the inhomogeneous ODE (suppressing $\delta, b, \underline{\xi}, \underline{F}, \bar{\xi}$, and $\bar{F}$ in the notation for $F$ )

$$
\frac{1}{2} \sigma^{2} \xi^{2} F^{\prime \prime}(\xi)+\mu \xi F^{\prime}(\xi)-r F(\xi)+\delta \xi+b=0,
$$
}

with the boundary conditions

$$
F(\underline{\xi})=\underline{F} \quad \text { and } \quad F(\bar{\xi})=\bar{F} .
$$

Recall that the general solution to the ODE (A.3) is

$$
F(\xi ; \delta, b, \underline{\xi}, \underline{F}, \bar{\xi}, \bar{F})=k_{1} \xi^{x_{1}}+k_{2} \xi^{x_{2}}+\frac{\delta \xi}{r-\mu}+\frac{b}{r}, \quad \xi \in[\underline{\xi}, \bar{\xi}],
$$

where $k_{1}$ and $k_{2}$ are determined by the boundary conditions. Simple manipulations reveal that

$$
k_{1}=\frac{1}{\Sigma}\left((\bar{F}-\Delta \bar{\xi}-B) \underline{\xi}^{x_{2}}-(\underline{F}-\Delta \underline{\xi}-B) \bar{\xi}^{x_{2}}\right)
$$

and

$$
k_{2}=\frac{1}{\Sigma}\left((\underline{F}-\Delta \underline{\xi}-B) \bar{\xi}^{x_{1}}-(\bar{F}-\Delta \bar{\xi}-B) \underline{\xi}^{x_{1}}\right) .
$$

${ }^{11}$ That it is true for any $\xi \in(\xi, \bar{\xi})$ follows directly. That it is also true for $\xi \in\{\xi, \bar{\xi}\}$ must 
The economic intuition behind this homogeneity property is quite trivial: if the unit of account was changed, e.g., from $\$$ to $€$, on all inputs, then also the value will change accordingly from being measured in $\$$ to being measured in $€$. This result heavily relies on the scaling invariant feature of the geometric Brownian motion and that everything except for monetary units is specified in rates.

With this machinery in place we return to the problem of finding the optimal dynamic capital structure of the firm and the values of debt and equity. Basically, debt and equity are claims of the form $F$ just derived. We just have to find $\delta, b, \underline{\xi}, \underline{F}, \bar{\xi}$, and $\bar{F}$ for both debt and equity.

In order to find the after-tax payout rate, $\delta \xi+b$, on debt and equity we need to know the tax rules and payout rates. Here, we briefly recap the structure from Section 2. Coupon payments paid out to the debt holders are expenses for the firm, i.e. they are subtracted from the EBIT before the firm pays corporate tax. Hence, the total tax paid on coupons is the personal interest tax paid by the debt holders. For dividends the firm must first pay tax on its EBT before dividends can be paid out to the equity holders. On top of that the equity holders pay dividend tax on dividends paid out. Hence, the after-tax payout rate, $\delta \xi+b$, on debt is specified as

$$
\delta \xi+b=\left(1-\tau_{i}\right) C
$$

be checked separately. It comes from the fact that $F(\underline{\xi})=\underline{F}$ and $F(\bar{\xi})=\bar{F}$. The reason why, e.g., $F(\bar{\xi})=\bar{F}$ is because if $\xi=\bar{\xi}$ then the upper boundary is hit immediately and therefore (i) there is no waiting time until one of the two boundaries will be hit and (ii) there is zero probability that the lower boundary will be hit before the upper boundary. 
and for equity it is specified as

$$
\delta \xi+b= \begin{cases}\left(1-\tau_{e}\right)(\xi-C), & \text { if } \xi \geq C, \\ \left(1-\epsilon \tau_{e}\right)(\xi-C), & \text { if } \xi<C .\end{cases}
$$

Here $\tau_{e}$ denotes the effective tax rate on dividends. That is,

$$
\tau_{e}=\tau_{c}+\left(1-\tau_{c}\right) \tau_{d}
$$

where $\tau_{c}$ denotes the corporate tax rate, and $\tau_{d}$ denotes the personal dividend tax rate. $\epsilon$ denotes the effective tax refund when EBT is negative. The values assigned to $\delta$ and $b$ for debt and equity are summarized in Table B.2. By adding the payout rates of debt and equity we see that there is a tax advantage to debt if and only if the effective tax rate on dividends is higher than the personal tax on interest payments, i.e. $\tau_{e}>\tau_{i}$, when EBT is positive, i.e. $\xi \geq C$. However, for $\xi<C$ it is possible that there can be a tax disadvantage to debt. This happens when $\epsilon \tau_{e}<\tau_{i}$. For the rest of the paper we assume that $\tau_{e}>\tau_{i}$ such that there is a tax advantage to debt for positive EBT. This implies that the optimal capital structure of the firm will include some debt.

[Table 2 about here.]

For a given (optimal) coupon rate, $C^{*}$, on the debt, and a given restructuring policy, $(\underline{\xi}, \bar{\xi})$ (determined endogenously in the model when the debt was issued, e.g. at date zero when the EBIT process was $\xi_{0}$ ), we must specify the value of debt and equity when one of the restructuring boundaries has been hit. However, contrary to a static capital structure model these values are not known since when the restructuring boundaries have been hit, the (possible new) owner will again issue debt and equity and continue operation. 
To establish some notation we denote these values (the notation is obvious) as $\underline{D}, \bar{D}, \underline{E}$, and $\bar{E}$. Furthermore, denote the earliest date after the debt issue when a restructuring boundary has been hit as $\tau$. Since the situation at date $\tau$, when the (possible new) owner of the whole firm reissues new debt, is exactly identical to the situation at date zero when the original entrepreneur issued the original debt - except that the EBIT process is now $\xi_{\tau}$ instead of $\xi_{0}$-we conjecture that the coupon rate of the newly issued debt will be $\frac{\xi_{\tau}}{\xi_{0}} C^{*}$ at date $\tau$, the new restructuring policy will be $\left(\frac{\xi_{\tau}}{\xi_{0}} \underline{\xi}, \frac{\xi_{\tau}}{\xi_{0}} \bar{\xi}\right)$, and the new boundary values will be $\frac{\xi_{\tau}}{\xi_{0}} \underline{D}, \frac{\xi_{\tau}}{\xi_{0}} \bar{D}, \frac{\xi_{\tau}}{\xi_{0}} \underline{E}$, and $\frac{\xi_{\tau}}{\xi_{0}} \bar{E}$. In fact, we will later prove that this conjecture is correct. We state our conjecture formally below.

Conjecture 1. 1. The optimal coupon rate $C^{*}$ determined just prior to issuing the debt at a given date $s$ when the EBIT process is $\xi_{s}$ can be written as

$$
C^{*}=c^{*} \xi_{s}
$$

for a given constant $c^{*}$.

2. The incentive compatible restructuring policy $(\underline{\xi}, \bar{\xi})$, which is common knowledge as soon as the coupon rate $C^{*}$ is fixed at a given date $s$ when the EBIT process is $\xi_{s}$, can be written as

$$
\underline{\xi}=d \xi_{s}
$$

and

$$
\bar{\xi}=u \xi_{s}
$$

for given constants $d \in(0,1)$ and $u \in(1, \infty)$.

3. The values of debt and equity when one of the boundaries (induced by the commonly known restructuring policy fixed by the optimally determined coupon rate at a given date $s$ when the EBIT process is $\xi_{s}$ ) has 
been hit can be written as

$$
\begin{aligned}
& \underline{D}=\underline{d} \xi_{s}, \\
& \bar{D}=\bar{d} \xi_{s}, \\
& \underline{E}=\underline{e} \xi_{s}
\end{aligned}
$$

and

$$
\bar{E}=\bar{e} \xi_{s}
$$

for given constants $\underline{d}, \bar{d}, \underline{e}$, and $\bar{e}$.

Given Conjecture 1 we can derive (and denote) the price at any given date $t$, when the EBIT process is $\xi_{t}$, of debt and equity issued at some date $s \leq t$, when the EBIT process was $\xi_{s}$, provided that the EBIT process $\left\{\xi_{u}\right\}_{u \in[s, t]}$ in the time period $[s, t)$ has stayed inside the interval $\left(d \xi_{s}, u \xi_{s}\right)$, as

$$
D\left(\xi_{t} ; \xi_{s}\right)=F\left(\xi_{t} ; 0,\left(1-\tau_{i}\right) c^{*} \xi_{s}, d \xi_{s}, \underline{d} \xi_{s}, u \xi_{s}, \bar{d} \xi_{s}\right)
$$

and

$$
E\left(\xi_{t} ; \xi_{s}\right)=F\left(\xi_{t} ; 1-\tau_{e},-\left(1-\tau_{e}\right) c^{*} \xi_{s}, d \xi_{s}, \underline{e} \xi_{s}, u \xi_{s}, \bar{e} \xi_{s}\right) .
$$

To be exact, the equity value, $E$, has only the form (A.7) if $c^{*} \leq d$. This is due to the asymmetric tax regime the equity holders face. They have to pay the tax rate $\tau_{e}$ when the firm's EBT is positive, but they can only deduct at the tax rate $\epsilon \tau_{e}$ when the firm's EBT is negative. Hence, if $c^{*} \in(d, u)$, the equity value is pieced together in the following way to ensure that it is one-time continuously differentiable

$E\left(\xi_{t} ; \xi_{s}\right)= \begin{cases}F\left(\xi_{t} ; 1-\epsilon \tau_{e},-\left(1-\epsilon \tau_{e}\right) c^{*} \xi_{s}, d \xi_{s}, \underline{e}_{s}, c^{*} \xi_{s}, e^{*} \xi_{s}\right), & \text { if } \xi_{t}<c^{*} \xi_{s}, \\ F\left(\xi_{t} ; 1-\tau_{e},-\left(1-\tau_{e}\right) c^{*} \xi_{s}, c^{*} \xi_{s}, e^{*} \xi_{s}, u \xi_{s}, \bar{e} \xi_{s}\right), & \text { if } \xi_{t} \geq c^{*} \xi_{s}\end{cases}$ 
Here, $e^{*}$ is the equity value when $\xi_{t}=c^{*}$ and $\xi_{s}=1$. This value is determined by requiring the equity value function, $E$, to be continuously differentiable in the first variable at the point $\xi_{t}=c^{*} \xi_{s}{ }^{12}$ Finally, if $c^{*} \geq u$, the firm always has negative earnings net of coupon payments, so $E$ has the form

$$
E\left(\xi_{t} ; \xi_{s}\right)=F\left(\xi_{t} ; 1-\epsilon \tau_{e},-\left(1-\epsilon \tau_{e}\right) c^{*} \xi_{s}, d \xi_{s}, \underline{e} \xi_{s}, u \xi_{s}, \bar{e} \xi_{s}\right) .
$$

\section{AppendixB. Verification of Conjecture 1 (Online appendix)}

In this appendix we verify that there exists solutions to debt and equity that fulfills Conjecture 1. Equations (5), (6), (7), and (8) immediately verify part 3 of Conjecture 1 and that

$$
\begin{aligned}
& \underline{d}=\min \{(1-\alpha) A d, D\}, \\
& \bar{d}=(1+\lambda) D, \\
& \underline{e}=\max \{(1-\alpha) A d-D, 0\},
\end{aligned}
$$

and

$$
\bar{e}=A u-(1+\lambda) D
$$

For given $c^{*}, d$, and $u$, the two constants $D$ and $E$ can be found by solving for the initial debt and equity values for $\xi_{t}=\xi_{s}=1$. That is, using the

\footnotetext{
${ }^{12}$ Formally, we have to add the condition that the equity value at the point where the two parts are pieced together in a one-time continuously differentiable way can be written as $e^{*} \xi_{s}$ to our Conjecture 1 . That is, we have to add to part 3 of Conjecture 1 that the value of equity, at the point where $\xi_{t}=c^{*} \xi_{s}$, can be written as

$$
E\left(c^{*} \xi_{s} ; \xi_{s}\right)=e^{*} \xi_{s}
$$

for a given constant $e^{*}$.
} 
expression of $F$ from equation (A.2) we have the following two equations in two unknowns ${ }^{13}$

$$
\begin{aligned}
D= & \Delta_{D}(1-d \underline{P}(1)-u \bar{P}(1))+B_{D}(1-\underline{P}(1)-\bar{P}(1)) \\
& +\min \{(1-\alpha) A d, D\} \underline{P}(1)+(1+\lambda) D \bar{P}(1)
\end{aligned}
$$

and

$$
\begin{aligned}
E= & \Delta_{E}(1-d \underline{P}(1)-u \bar{P}(1))+B_{E}(1-\underline{P}(1)-\bar{P}(1)) \\
& +\max \{(1-\alpha) A d-D, 0\} \underline{P}(1)+(A u-(1+\lambda) D) \bar{P}(1) .
\end{aligned}
$$

Here,

$$
\Delta_{D}=0, \quad \Delta_{E}=\frac{\left(1-\tau_{e}\right)}{r-\mu}, \quad B_{D}=\frac{c^{*}}{r}, \quad \text { and } \quad B_{E}=\frac{-\left(1-\tau_{e}\right) c^{*}}{r} .
$$

For a given $c^{*}$, we can find $d$ and $u$ by the two smooth pasting conditions, equations (9) and (10). Unfortunately, these two equations in two unknowns can only be solved numerically. However, by Euler's theorem $E_{1}\left(\xi_{t} ; \xi_{s}\right)$ is positive homogeneous of degree zero because $E\left(\xi_{t} ; \xi_{s}\right)$ itself is positive homogeneous of degree one, cf. equation (3). That is,

$$
E_{1}\left(h \xi_{t} ; h \xi_{s}\right)=E_{1}\left(\xi_{t} ; \xi_{s}\right)
$$

for any $\xi_{t} \in\left[d \xi_{s}, u \xi_{s}\right]$ and $h \in \mathbb{R}_{+}$. Hence, equations (9) and (10) are identical independent of the actual level of $\xi_{0}$. Therefore, the solutions $d$ and $u$ are also independent of the actual level of $\xi_{0}$. That is, we have verified part 2 of Conjecture $1 .^{14}$

\footnotetext{
${ }^{13}$ If $c^{*} \in(d, u)$, there are three unknowns: $D, E$, and $e^{*}$. The third equation comes from differentiability of the equity function, $E$, at $\xi_{t}=c^{*} \xi_{s}$, cf. equation (A.8).

${ }^{14}$ In fact, this positive homogeneity property of degree zero of $E_{1}\left(\xi_{t} ; \xi_{s}\right)$ can also be used to verify that $e^{*}$ is independent of the actual level of $\xi_{0}$. This verifies the missing conjecture in the case where $c^{*} \in(d, u)$, cf. footnote 12 .
} 
Finally, the optimal coupon rate of the debt, which is determined just prior to the debt issue at date zero, is given by

$$
C^{*}=\underset{C \in \mathbb{R}_{+}}{\operatorname{argmax}} A\left(\xi_{0}\right) .
$$

That is so because it is the original entrepreneur who determines the coupon rate of the perpetual debt that he or she would like to issue. Naturally, the entrepreneur sets the coupon rate in order to maximize his or her own value. Moreover, rewriting $C$ as $c \xi_{0}$ gives exactly the same optimization problem since $\xi_{0}$ is positive

$$
C^{*}=\underset{C \in \mathbb{R}_{+}}{\operatorname{argmax}} A\left(\xi_{0}\right)=\xi_{0}\left(\underset{c \in \mathbb{R}_{+}}{\operatorname{argmax}} \frac{A\left(\xi_{0}\right)}{\xi_{0}}\right) .
$$

Plugging in the definition of $A\left(\xi_{0}\right)$ from equation (4) gives

$$
\begin{aligned}
& c^{*}=\underset{c \in \mathbb{R}_{+}}{\operatorname{argmax}} \frac{E\left(\xi_{0} ; \xi_{0}\right)+(1-k) D\left(\xi_{0} ; \xi_{0}\right)}{\xi_{0}} \\
&=\underset{c \in \mathbb{R}_{+}}{\operatorname{argmax}}\left(\frac{F\left(\xi_{0} ; 1-\tau_{e},-\left(1-\tau_{e}\right) c \xi_{0}, d(c) \xi_{0}, \underline{e}(c) \xi_{0}, u(c) \xi_{0}, \bar{e}(c) \xi_{0}\right)}{\xi_{0}}\right. \\
&\left.\quad+(1-k) \frac{F\left(\xi_{0} ; 0,\left(1-\tau_{i}\right) c \xi_{0}, d(c) \xi_{0}, \underline{d}(c) \xi_{0}, u(c) \xi_{0}, \bar{d}(c) \xi_{0}\right)}{\xi_{0}}\right) \\
&=\underset{c \in \mathbb{R}_{+}}{\operatorname{argmax}}\left(F\left(1 ; 1-\tau_{e},-\left(1-\tau_{e}\right) c, d(c), \underline{e}(c), u(c), \bar{e}(c)\right)\right. \\
&\left.\quad+(1-k) F\left(1 ; 0,\left(1-\tau_{i}\right) c, d(c), \underline{d}(c), u(c), \bar{d}(c)\right)\right) .
\end{aligned}
$$

Note that we have emphasized the dependence of $d, u, \underline{d}, \bar{d}, \underline{e}$, and $\bar{e}$ on the given coupon rate parameter, $c$, cf. part 2 and 3 of Conjecture 1. Finally, notice that the optimal coupon rate parameter, $c^{*}$, in the above optimization is independent of the initial level $\xi_{0}$ so we have verified the missing part (part 1) in Conjecture 1. That is, we have now verified that there exists a fixed-point solution to our debt and equity valuation problem giving us solutions to the value of debt and equity fulfilling Conjecture 1. Because 
of our conjecture-verification method of finding the fixed-point solution, we cannot rule out that there might be other fixed-point solutions which do not fulfill Conjecture 1. 


\begin{tabular}{ccc}
\hline \hline & $\delta$ & $b$ \\
\hline$D$ & 0 & $\left(1-\tau_{i}\right) C$ \\
$E_{\xi \geq C}$ & $1-\tau_{e}$ & $-\left(1-\tau_{e}\right) C$ \\
$E_{\xi<C}$ & $1-\epsilon \tau_{e}$ & $-\left(1-\epsilon \tau_{e}\right) C$ \\
\hline$D+E_{\xi \geq C}$ & $1-\tau_{e}$ & $\left(\tau_{e}-\tau_{i}\right) C$ \\
$D+E_{\xi<C}$ & $1-\epsilon \tau_{e}$ & $\left(\epsilon \tau_{e}-\tau_{i}\right) C$ \\
\hline \hline
\end{tabular}

Table B.2: Values for $\delta$ and $b$ for debt $(D)$ and equity $(E)$ both when EBT is positive and when it is negative. 